\title{
Stress Corrosion Cracking in Al-Zn-Mg-Cu Aluminum Alloys in Saline Environments
}

\author{
N.J. HENRY HOLROYD and G.M. SCAMANS
}

Stress corrosion cracking of $\mathrm{Al}-\mathrm{Zn}-\mathrm{Mg}-\mathrm{Cu}(\mathrm{AA} 7 \mathrm{xxx}$ ) aluminum alloys exposed to saline environments at temperatures ranging from $293 \mathrm{~K}$ to $353 \mathrm{~K}\left(20^{\circ} \mathrm{C}\right.$ to $\left.80{ }^{\circ} \mathrm{C}\right)$ has been reviewed with particular attention to the influences of alloy composition and temper, and bulk and local environmental conditions. Stress corrosion crack (SCC) growth rates at room temperature for peak- and over-aged tempers in saline environments are minimized for $\mathrm{Al}-\mathrm{Zn}-\mathrm{Mg}-\mathrm{Cu}$ alloys containing less than $\sim 8 \mathrm{wt}$ pct $\mathrm{Zn}$ when $\mathrm{Zn} / \mathrm{Mg}$ ratios are ranging from 2 to 3 , excess magnesium levels are less than $1 \mathrm{wt}$ pct, and copper content is either less than $\sim 0.2 \mathrm{wt}$ pct or ranging from 1.3 to $2 \mathrm{wt}$ pct. A minimum chloride ion concentration of $\sim 0.01 \mathrm{M}$ is required for crack growth rates to exceed those in distilled water, which insures that the local solution $\mathrm{pH}$ in crack-tip regions can be maintained at less than 4 . Crack growth rates in saline solution without other additions gradually increase with bulk chloride ion concentrations up to around $0.6 \mathrm{M} \mathrm{NaCl}$, whereas in solutions with sufficiently low dichromate (or chromate), inhibitor additions are insensitive to the bulk chloride concentration and are typically at least double those observed without the additions. DCB specimens, fatigue pre-cracked in air before immersion in a saline environment, show an initial period with no detectible crack growth, followed by crack growth at the distilled water rate, and then transition to a higher crack growth rate typical of region 2 crack growth in the saline environment. Time spent in each stage depends on the type of precrack ("pop-in" vs fatigue), applied stress intensity factor, alloy chemistry, bulk environment, and, if applied, the external polarization. Apparent activation energies $\left(E_{\mathrm{a}}\right)$ for SCC growth in $\mathrm{Al}-\mathrm{Zn}-\mathrm{Mg}-\mathrm{Cu}$ alloys exposed to $0.6 \mathrm{M} \mathrm{NaCl}$ over the temperatures ranging from $293 \mathrm{~K}$ to $353 \mathrm{~K}\left(20^{\circ} \mathrm{C}\right.$ to $\left.80^{\circ} \mathrm{C}\right)$ for under-, peak-, and over-aged low-copper-containing alloys $(<0.2 \mathrm{wt}$ pct) are typically ranging from 80 to $85 \mathrm{~kJ} / \mathrm{mol}$, whereas for high-copper-containing alloys (> 0.8 wt pct), they are typically ranging from 20 to $40 \mathrm{~kJ} / \mathrm{mol}$ for under- and peak-aged alloys, and based on limited data, around $85 \mathrm{~kJ} / \mathrm{mol}$ for over-aged tempers. This means that crack propagation in saline environments is most likely to occur by a hydrogen-related process for low-copper-containing $\mathrm{Al}-\mathrm{Zn}-\mathrm{Mg}-\mathrm{Cu}$ alloys in under-, peak- and over-aged tempers, and for high-copper alloys in under- and peak-aged tempers. For over-aged high-copper-containing alloys, cracking is most probably under anodic dissolution control. Future stress corrosion studies should focus on understanding the factors that control crack initiation, and insuring that the next generation of higher performance $\mathrm{Al}-\mathrm{Zn}-\mathrm{Mg}-\mathrm{Cu}$ alloys has similar longer crack initiation times and crack propagation rates to those of the incumbent alloys in an over-aged condition where crack rates are less than $1 \mathrm{~mm} / \mathrm{month}$ at a high stress intensity factor.

DOI: $10.1007 / \mathrm{s} 11661-012-1528-3$

(C) The Minerals, Metals \& Materials Society and ASM International 2012

\section{INTRODUCTION}

STRESS corrosion crack (SCC) growth measurements, using pre-cracked $\mathrm{Al}-\mathrm{Zn}-\mathrm{Mg}-\mathrm{Cu}$ alloys test specimens exposed to saline environments, have been in widespread use since the late-1960s. ${ }^{[1-4]}$ Most studies, as summarized by Hyatt, ${ }^{[5]}$ have used bolt-loaded double cantilever beam (DCB) test specimens ${ }^{[4]}$ with a

N.J. HENRY HOLROYD, Consultant in Riverside, CA 92506 , and is also Adjunct Professor with Case Western Reserve University, Cleveland, OH 44106. Contact e-mail: henry.holroyd@luxfer.net G.M. SCAMANS, Chief Scientist, is with the Innoval Technologies, Banbury, Oxon OX16 1TQ, U.K., and is also Professor of Metallurgy with Brunel University, Uxbridge, Middlesex, UB8 3PH.

Manuscript submitted July 31, 2012.

Article published online November 27, 2012 short mechanical "pop-in" or fatigue pre-cracks extending from a machined notch, exposed under fixed displacement loading conditions with crack growth monitored under a decreasing stress intensity factor.

Crack growth rates for most commercial Al-Zn-Mg$\mathrm{Cu}$ alloys are reproducible for a given alloy composition and temper, when tested in a specific environment, as shown in Figure 1, for various batches of 25-mm-thick commercial AA7075-T651 alloy plate fully immersed in 0.5 through $0.6 \mathrm{M} \mathrm{NaCl}$ at $298 \mathrm{~K}\left(25^{\circ} \mathrm{C}\right) .{ }^{[5-9]}$ However, significant scatter can occur in samples from thick plate (>50 mm) because of local differences in composition, microstructure, and quench rate ${ }^{[10,11]}$ and for alloys containing between 0.2 and $\sim 0.8$ wt pct copper, where crack growth rates are often at least an order of magnitude higher than those measured for alloys with either lower or higher-copper content. Almost all studies 


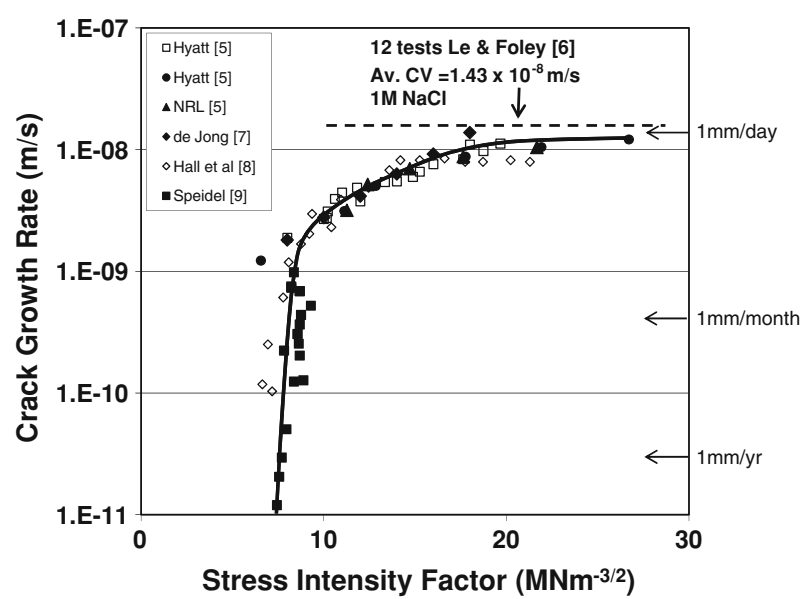

Fig. 1-Stress corrosion crack (SCC) growth rate as a function of the applied stress intensity factor for 25 -mm-thick plate of AA7075T651 fully immersed in an aqueous $0.6 \mathrm{M}$ sodium chloride solution at room temperature.

have used samples from plate or extrusions in either in the peak-aged (T6) temper or over-aged tempers (T76 and T73), and very little study has been carried out on under-aged tempers where crack growth rates can be much higher.

DCB stress corrosion test results are usually reported as a calculated crack growth rate as a function of the applied stress intensity factor, $K$, i.e., the $\mathrm{V}-\mathrm{K}$ curve, without reporting the crack length as a function of time. Where such information is available, it is clear that initial crack rates are significantly lower than subsequent rates $^{[12-14]}$ particularly for fatigue pre-cracked test specimens. An excellent example of crack growth rates significantly increasing during conventional bolt-loaded DCB testing has been obtained by analysis of the crack length-time data provided by Deffenbaugh ${ }^{[14]}$ for an over-aged Al-7.8Zn-2.2Mg-1.6Cu alloy (AA7249T76511). Average crack length as a function of time, reproduced in Figure 2, shows that the initial crack growth rate remains at around $6.1 \times 10^{-10} \mathrm{~m} / \mathrm{s}$ for over $1000 \mathrm{~h}$, independent of the bulk solution chloride concentration, and then suddenly increases to around $2.4 \times 10^{-9} \mathrm{~m} / \mathrm{s}$, despite the applied stress intensity factor having been reduced. These results are also summarized in Table I.

We have undertaken a detailed evaluation of the published SCC growth rate measurements, which shows crack growth rates may be either highly or weakly temper-sensitive, or may show different temperature dependencies between room temperature and up to around $353 \mathrm{~K}\left(80^{\circ} \mathrm{C}\right)$ and frequently undergo transitions to higher rates following a period of much slower crack growth.

To simplify this analysis, we have divided $\mathrm{Al}-\mathrm{Zn}-\mathrm{Mg}$ $\mathrm{Cu}$ alloy compositions into four categories, based on copper content as shown in Table II.

The earliest studies evaluating the chemical compositions of wrought $\mathrm{Al}-\mathrm{Zn}-\mathrm{Mg}$ alloys, published around 1940, involved relatively high-purity ternary alloys prepared under laboratory conditions and mechanical properties gradually increased with increasing zinc and

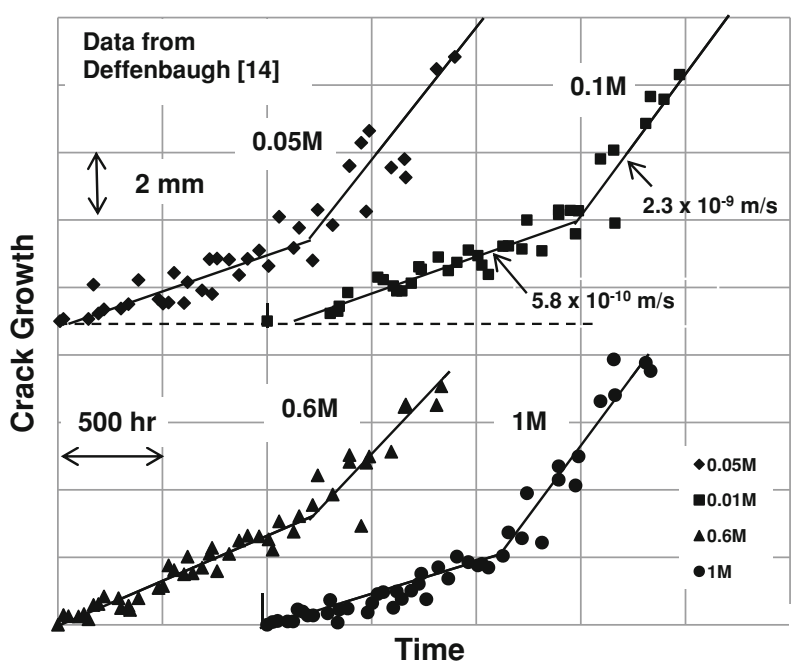

Fig. 2-Average SCC growth as a function of time calculated using data provided by Deffenbaugh ${ }^{[14]}$ for AA7249-T76511 (Initial $K$ $\sim 22 \mathrm{MNm}^{-3 / 2}$ ).

magnesium contents up to a combined content of about 9 wt pct, greater than which alloys strength and ductility were adversely effected by brittleness developing after age-hardening and fracture becoming intergranular. Further studies during the mid-1940s on commercially pure alloys, which indicated the additions of copper, chromium, and/or manganese were potentially beneficial, led to preferred alloy compositions ranging from 4 to 6 pet zinc, 2.5 to 3 pet magnesium, and copper contents up to a maximum of around $0.5 \mathrm{wt}$ pet, along with minor additions of manganese and/or chromium to limit grain growth, and in the case of chromium, to also improve corrosion resistance. Further details of these studies are provided elsewhere. ${ }^{[15]}$

Initial commercial applications of the low-coppercontaining Al-Zn-Mg-Cu alloys, during mid-1960s, involved welded structures ${ }^{[16]}$ restricted an alloy's total zinc plus magnesium content to range from 5 to $7 \mathrm{wt} \mathrm{pct}$ ( 3 to 5 pet $\mathrm{Zn}$ and 1.2 to 2.8 pet $\mathrm{Mg}$ ) to maximize strength, while providing an acceptable SCC resistance, and restricting the copper level to less than $0.2 \mathrm{wt}$ pct to avoid adverse effects on weldability. ${ }^{[17]}$

A landmark, but rarely referenced, study conducted in the late 1940 s by Cook et al. ${ }^{[15]}$ was undertaken to establish a range of alloy compositions for the commercial casting and fabrication of wrought high-coppercontaining $\mathrm{Al}-\mathrm{Zn}-\mathrm{Mg}-\mathrm{Cu}$ alloys that provided maximum strength along with adequate ductility and corrosion resistance when heat treated. This comprehensive study involved alloys containing up to 12 pct zinc, $3.5 \mathrm{pct}$ magnesium, and 3 pct copper, along with additions of chromium, manganese, iron, and silicon, with the effects on mechanical properties and corrosion resistance being evaluated independently for each of the elemental additions. This classic study identified a nominal optimum alloy composition of $\mathrm{Al}-6.5 \mathrm{Zn}-1.8 \mathrm{Mg}-1.5 \mathrm{Cu}$, which is remarkably similar to commercial $7 \mathrm{xxx}$ series alloys' compositions used today over 60 years later, and pre-dated the registration of AA7075 with the Aluminum Association in 1954. 
Table I. SCC Growth Characteristics for Cracking Growth Initiating from Fatigue Pre-Cracked DCB Specimens of AA7249-T76511 Exposed to Various Saline Solutions ${ }^{[14]}$

\begin{tabular}{|c|c|c|c|c|c|c|}
\hline \multirow[b]{3}{*}{$\mathrm{NaCl}(\mathrm{M})$} & \multicolumn{4}{|c|}{ Initial Crack Growth from Pre-crack } & \multicolumn{2}{|c|}{ Region 2 Crack Growth } \\
\hline & \multirow[b]{2}{*}{ Initiation Time $(\mathrm{h})$} & \multicolumn{3}{|c|}{ Slow Crack Growth } & \multirow{2}{*}{$\begin{array}{c}K\left(\mathrm{MNm}^{-3 / 2}\right) \\
\text { Transition }\end{array}$} & \multirow[b]{2}{*}{$\mathrm{CV}(\mathrm{m} / \mathrm{s})$} \\
\hline & & Distance (mm) & Time (h) & $\mathrm{CV}(\mathrm{m} / \mathrm{s})$ & & \\
\hline 0.05 & $\sim 100$ & 2.6 & 1200 & $6.0 \times 10^{-10}$ & 17.8 & $2.8 \times 10^{-9}$ \\
\hline 0.1 & $\sim 100$ & 2.75 & 1325 & $5.8 \times 10^{-10}$ & 17.6 & $2.3 \times 10^{-9}$ \\
\hline 0.6 & $<24$ & 3.35 & 1200 & $7.8 \times 10^{-10}$ & 16.9 & $1.7 \times 10^{-9}$ \\
\hline 1 & $<24$ & 1.9 & 1120 & $4.7 \times 10^{-10}$ & 18.7 & $2.7 \times 10^{-9}$ \\
\hline
\end{tabular}

Table II. Commercial Al-Zn-Mg-Cu Alloys (7xxx Series) Categorized in Terms of Alloys' Copper Content

\begin{tabular}{|c|c|c|c|c|}
\hline Copper Level & Alloy & $\mathrm{Zn}(\mathrm{Wt}$ Pct $)$ & $\mathrm{Mg}(\mathrm{Wt}$ Pct) & $\mathrm{Cu}(\mathrm{Wt}$ Pct) \\
\hline \multirow[t]{2}{*}{ Copper-Free } & Al-Zn-Mg (HP) & 3 to 7 & 1 to 3 & $<0.01$ \\
\hline & AA7146 & 6.6 to 7.6 & 1.1 to 1.6 & $<0.05$ \\
\hline \multirow[t]{3}{*}{ Low $(0.01$ to 0.2$)$} & AA7017 & 4.0 to 5.0 & 2.0 to 3.0 & $<0.2$ \\
\hline & AA7018 & 4.5 to 5.5 & 0.7 to 1.5 & $<0.2$ \\
\hline & AA7039 & 3.5 to 4.5 & 2.3 to 3.3 & 0.1 \\
\hline \multirow[t]{2}{*}{ Medium (0.2 to 0.8$)$} & AA7079 & 3.8 to 4.8 & 2.9 to 3.7 & 0.4 to 0.8 \\
\hline & AA7022* & 4.3 to 5.2 & 2.6 to 3.7 & 0.5 to 1.0 \\
\hline \multirow[t]{6}{*}{ High $(>0.8)$} & AA7075 & 5.1 to 6.1 & 2.1 to 2.9 & 1.2 to 2.0 \\
\hline & AA7010 & 5.7 to 6.7 & 2.1 to 2.6 & 1.5 to 2.0 \\
\hline & AA 7050 & 5.7 to 6.7 & 1.9 to 2.6 & 2.0 to 2.6 \\
\hline & AA7085 & 7.0 to 8.0 & 1.2 to 1.8 & 1.3 to 2.0 \\
\hline & AA 7055 & 7.6 to 8.4 & 1.8 to 2.3 & 2.0 to 2.6 \\
\hline & N707 & 10.5 & 2.4 & 1.9 \\
\hline
\end{tabular}

* Cu content for AA7022 may exceed 0.8 wt pct.

In the late 1970 s, Gruhl ${ }^{[18]}$ provided SCC data for low- and high-copper-containing $\mathrm{Al}-\mathrm{Zn}-\mathrm{Mg}-\mathrm{Cu}$ alloys with a given total zinc plus magnesium content showing that a maximum resistance to SCC occurred when a $\mathrm{Zn} /$ $\mathrm{Mg}$ alloy's ratio is ranging from 2.7 to 3, but noted that the $\mathrm{Zn} / \mathrm{Mg}$ ratios for many commercial $7 \mathrm{xxx}$ series alloys fall well outside this range.

The use here of an alloy's "excess magnesium" content as an indicator of its stress corrosion susceptibility was inspired by Anderson' ${ }^{[19]}$ claim that an Al$\mathrm{Zn}-\mathrm{Mg}$-Cu alloy's SCC resistance was optimized with a stoichiometrically balanced chemical composition.

Despite many claims to the contrary, none of the microstructural parameters, such as grain boundary $(\mathrm{gb})$, precipitate size and/or spacing, gb precipitate freezone (PFZ) width or preferential slip in PFZ, matrix precipitate size/distribution and deformation characteristics, solute profiles in PFZ or gb segregation, etc., has yet been identified, which can uniquely control the SCC of $7 x x x$ series aluminum alloys. ${ }^{[20]}$ This is mainly due to the near-impossibility of independently varying the above microstructural features and hence the correlation of SCC susceptibility with a single parameter. Detailed information supporting this argument is summarized elsewhere. ${ }^{[20]}$ Recently, some progress has been achieved in terms of linking the improved SCC resistance for high-copper-containing $\mathrm{Al}-\mathrm{Zn}-\mathrm{Mg}-\mathrm{Cu}$ alloys with overaging, to copper's incorporation into $\mathrm{gb} \mathrm{MgZn}_{2}$ precipitates. ${ }^{[10,11]}$

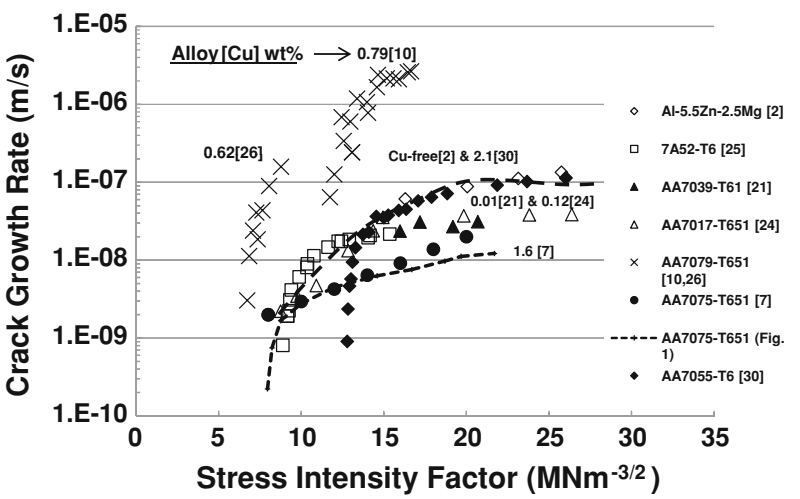

Fig. 3-Typical SCC growth rates for $\mathrm{Al}-\mathrm{Zn}-\mathrm{Mg}-\mathrm{X}$ pct. $\mathrm{Cu}$ alloys exposed to 0.5 through $0.6 \mathrm{M} \mathrm{NaCl}$ solutions at $295 \mathrm{~K}$ through $300 \mathrm{~K}\left(22{ }^{\circ} \mathrm{C}\right.$ to $27^{\circ} \mathrm{C}$ ) (Note AA7017-T651 SCC is in natural seawater $^{[24]}$.

\section{SCC OF Al-Zn-Mg-Cu ALLOYS IN 0.5 TO 0.6 M NaCI AT ROOM TEMPERATURE}

\section{A. Effects of Alloy Composition and Temper}

SCC growth rate measurements that clearly show that SCC resistance is not a simple function of coppercontaining are plotted in Figure 3, as a function of the applied stress intensity factor, for peak-aged $\mathrm{Al}-\mathrm{Zn}-\mathrm{Mg}$ $\mathrm{Cu}$ alloys exposed to a $0.6 \mathrm{M} \mathrm{NaCl}$ solution. 


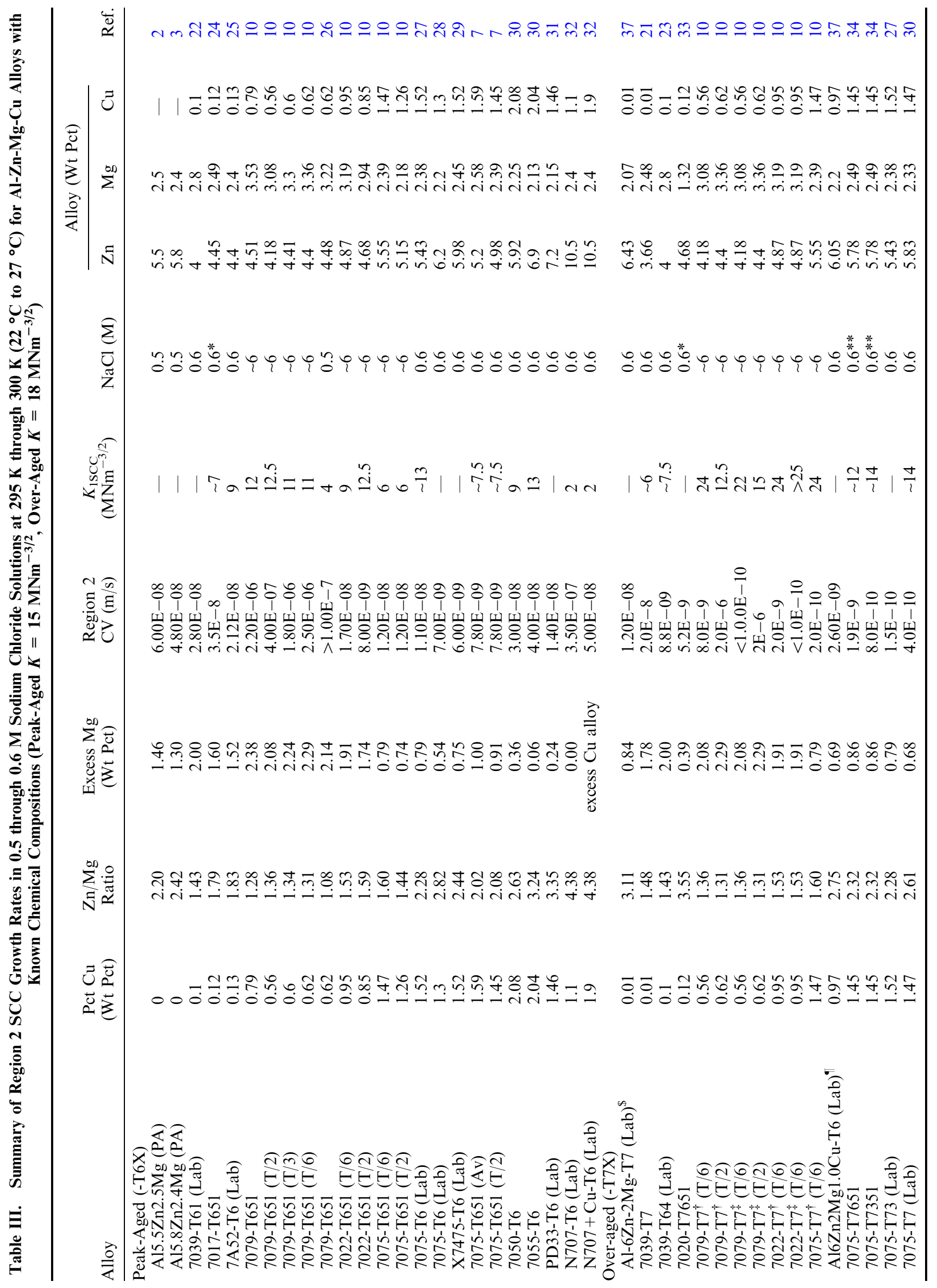




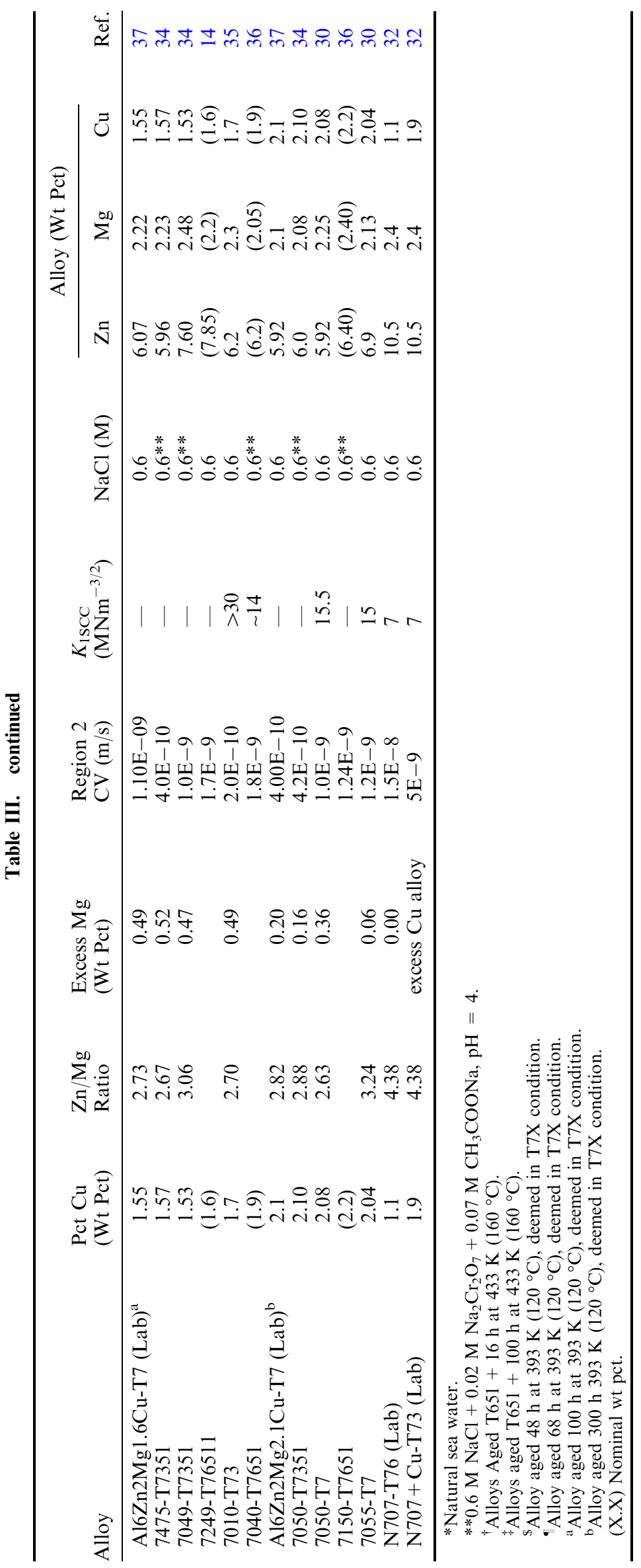




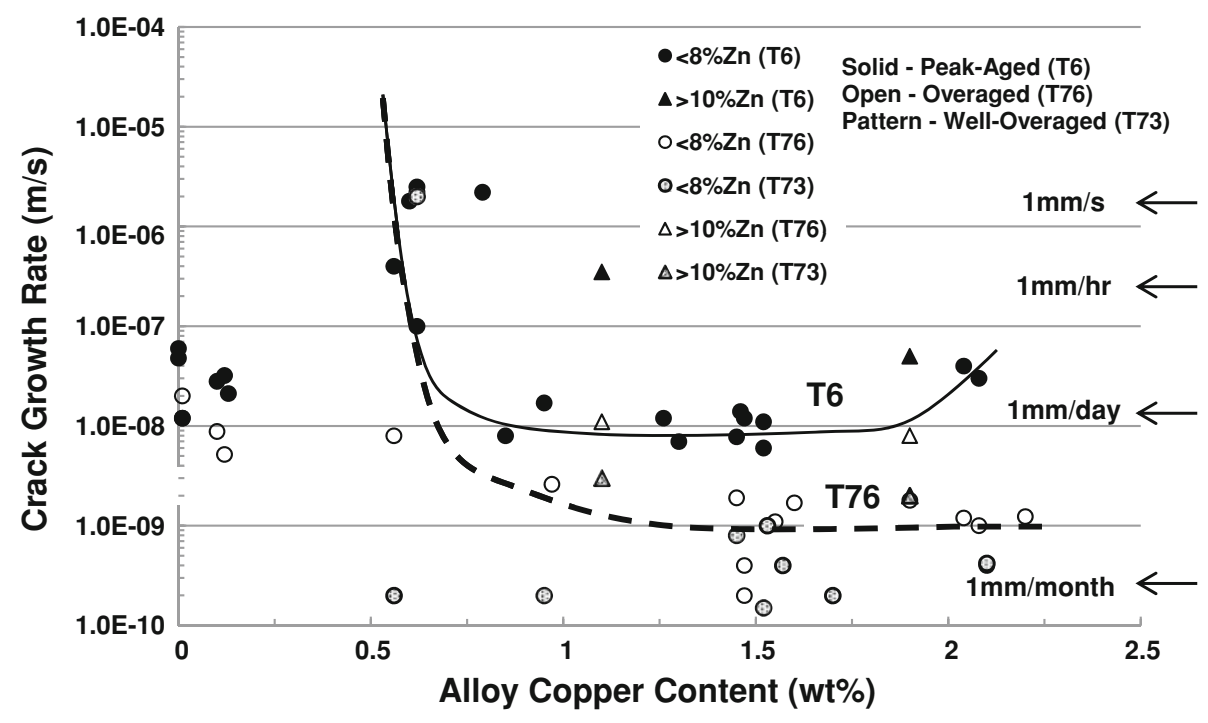

Fig. 4-Region $2 \mathrm{SCC}$ growth rates for Al-Zn-Mg-Cu alloys as a function of copper content in $0.6 \mathrm{M}$ sodium chloride solution (Data extracted from References quoted in Table III).

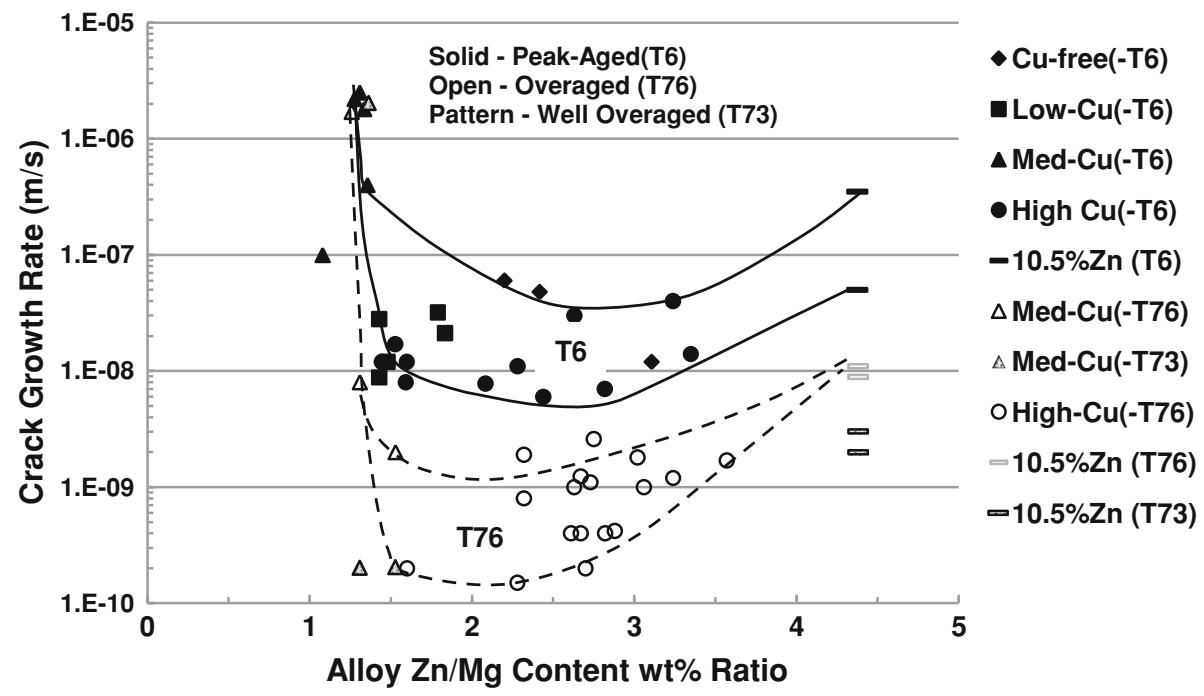

Fig. 5- Region 2 SCC growth rates for $\mathrm{Al}-\mathrm{Zn}-\mathrm{Mg}-\mathrm{Cu}$ alloys as a function of $\mathrm{Zn} / \mathrm{Mg}$ ratio for alloys in $0.6 \mathrm{M}$ sodium chloride solution (Data extracted from References quoted in Table III).

Table III is a compilation of region $2\left(K>14 \mathrm{MNm}^{-3 /}\right.$ $\left.{ }^{2}\right)$ SCC growth rates for peak- and over-aged Al-Zn-Mg$\mathrm{Cu}$ alloys loaded in the short transverse direction where actual alloy chemical compositions were provided. ${ }^{[2,3,7,10,14,21-37]}$ Figures 4, 5, and 6 are graphical representations of the region 2 crack growth rates from Table III, showing the effects of copper-containing alloy, $\mathrm{Zn} / \mathrm{Mg}$ ratio, ${ }^{[18]}$ and excess magnesium content (calculated using Anderson's ${ }^{[19]}$ method to estimate the stoichiometric "balance").

Evaluation of this data shows that the SCC performance of alloys containing less than 0.2 pct or more than about 0.8 wt pet copper is predictable based on $\mathrm{Zn} / \mathrm{Mg}$ ratio, excess magnesium content, and temper. Predictability for alloys with copper contents between $\sim 0.2$ and $\sim 0.8$ pct wt copper is less straightforward, particularly if a low $\mathrm{Zn} / \mathrm{Mg}$ ratio is combined with a high excess $\mathrm{Mg}$ content, where highly SCC susceptible alloys remain so even after significant over-aging (this applies to most commercial AA7079 alloy chemical compositions). This analysis shows that only $0.8 \mathrm{wt}$ pct copper is required for over-aging to be beneficial for SCC resistance rather than the widely accepted level of $1 \mathrm{wt}$ pct copper. Recent study ${ }^{[10,11]}$ has demonstrated that reducing the quench rate after solution heat treatment for medium-coppercontaining $\mathrm{Al}-\mathrm{Zn}-\mathrm{Mg}-\mathrm{Cu}$ alloys with copper contents as low as $0.56 \mathrm{wt}$ pct copper can lead to over-aging, improving their resistance to SCC. However, this is accompanied by a large reduction in alloy strength, with the T76 temper having an equivalent SCC susceptibility to peak-aged alloys with copper contents greater than $0.8 \mathrm{wt}$ pet copper, as shown in Table III.

For high-copper-containing alloys, the beneficial effect of over-aging to improve SCC resistance has been 


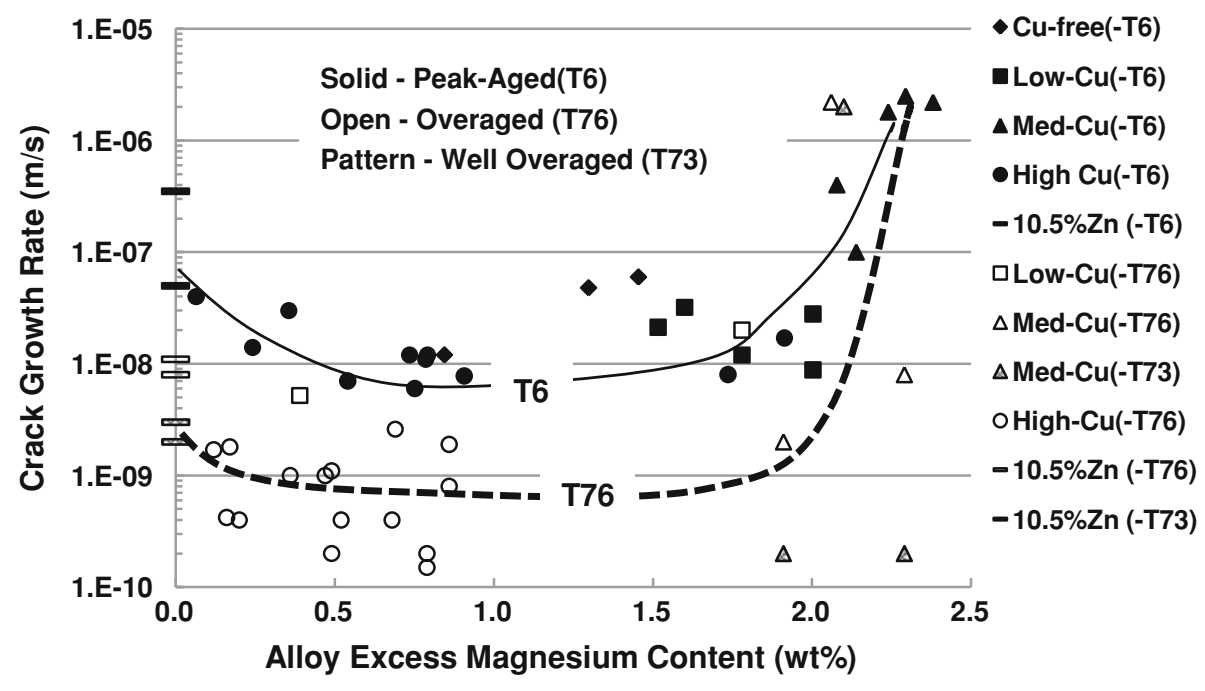

Fig. 6-Region $2 \mathrm{SCC}$ growth rates for $\mathrm{Al}-\mathrm{Zn}-\mathrm{Mg}$-Cu alloys as a function of excess magnesium content for alloys in $0.6 \mathrm{M}$ sodium chloride solution (Data extracted from References quoted in Table III).

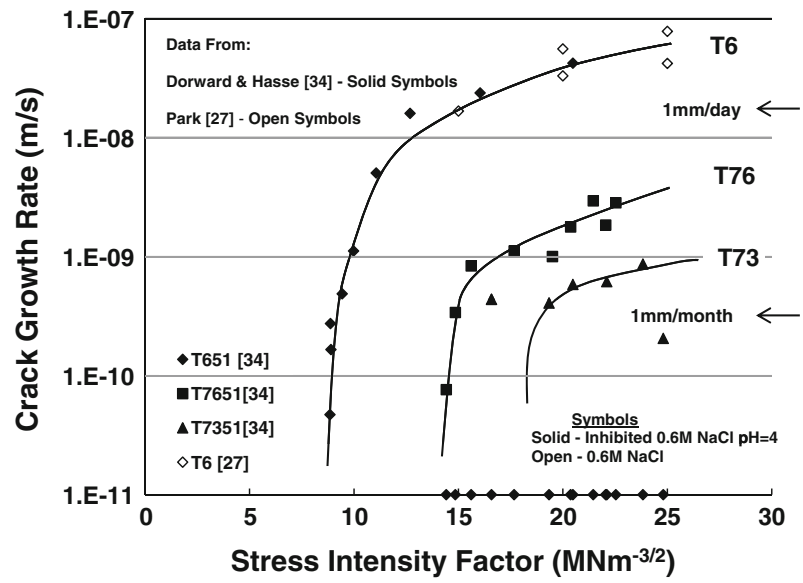

Fig. 7-Influence of alloy temper on the SCC growth rate for AA7075-T651 exposed to saline solutions containing $0.6 \mathrm{M} \mathrm{NaCl}$ with and without a sodium dichromate inhibitor addition.

commercially exploited for many years ${ }^{[9]}$ and an example of this behavior for an alloy containing around 1.5 pet copper (AA7075) is shown in Figure 7. Based on the information in Figures 4 through 6, alloy compositions containing less than 8 pct zinc that minimize SCC susceptibility have a $\mathrm{Zn} / \mathrm{Mg}$ ratio of 2 to 3 (as originally proposed by $\mathrm{Gruhl}^{[18]}$ ), less than $1 \mathrm{wt}$ pct excess magnesium and copper levels either less than $\sim 0.2 \mathrm{wt}$ pet or ranging from 1.3 to $2 \mathrm{wt}$ pet.

The SCC growth rate results of Sakar et al. ${ }^{[37]}$ for a series of copper-containing variants of an $\mathrm{Al}-6 \mathrm{Zn}-2 \mathrm{Mg}$ $\mathrm{X}$ pct. $\mathrm{Cu}$ alloy exposed to $0.53 \mathrm{M} \mathrm{NaCl}$, have been included as "over-aged" because the quoted heat treatments would have generated over-aged tempers and their SCC growth results when considered in terms of copper content, $\mathrm{Zn} / \mathrm{Mg}$ ratio and excess magnesium level, are consistent with that of other over-aged Al-Zn$\mathrm{Mg}-\mathrm{Cu}$ alloys.

\section{B. Influence of Temperature on Crack Growth}

Several researchers have evaluated the temperature dependency of SCC of Al- $\mathrm{Zn}-\mathrm{Mg}-\mathrm{Cu}$ alloys exposed to saline solutions. ${ }^{[21-23,38-55]}$ The earliest studies, conducted during the 1960s on copper-free and low-copper-containing $\mathrm{Al}-\mathrm{Zn}-\mathrm{Mg}-\mathrm{Cu}$ alloys, used smooth test specimens loaded under either constant load or constant strain conditions. The apparent activation energy data generated in these studies were sensitive to the test method employed ${ }^{[44]}$ and included contributions from both crack initiation and crack propagation, especially when the former involved "disturbed layers" generated during alloy fabrication. ${ }^{[56]}$ Subsequent studies generally used DCB test specimens, and the apparent activation energies were derived from region 2 crack propagation rates over a range of temperatures.

Apparent activation energy $\left(E_{\mathrm{a}}\right)$ for SCC propagation from the published literature for $\mathrm{Al}-\mathrm{Zn}-\mathrm{Mg}-\mathrm{Cu}$ alloys in aqueous saline solutions is shown in Table IV, with details of alloy composition, test environment and test method employed. SCC growth rates under region 1 and 2 loading conditions for low- and high-copper-containing $\mathrm{Al}-\mathrm{Zn}-\mathrm{Mg}-\mathrm{Cu}$ alloys in $0.6 \mathrm{M} \mathrm{NaCl}$ at various temperatures from room temperature up to around $353 \mathrm{~K}\left(80^{\circ} \mathrm{C}\right)$ are shown in Figure 8 . The only data available for medium-copper-containing alloys were those provided by Speidel and Hyatt ${ }^{[9,47}$ for AA7079T651 exposed to $5 \mathrm{M}$ KI solution, which included additional stimulation by external anodic polarization at $-700 \mathrm{mV}_{\mathrm{SCE}}$, Figure 8 .

There are no sufficient data available to fully quantify the influence of alloy temper on the apparent activation energy, $E_{\mathrm{a}}$ for SCC propagation. Data available for lowcopper-containing $\mathrm{Al}-\mathrm{Zn}-\mathrm{Mg}-\mathrm{Cu}$ alloys suggests that $E_{\mathrm{a}}$ is relatively insensitive to alloy temper for temperatures greater than room temperature up to around $373 \mathrm{~K}$ $\left(100{ }^{\circ} \mathrm{C}\right)$, with under-, peak- and over-aged alloys all having activation energies ranging from 75 to $100 \mathrm{~kJ} /$ mol under region 1 and 2 loading conditions, Table IV. 


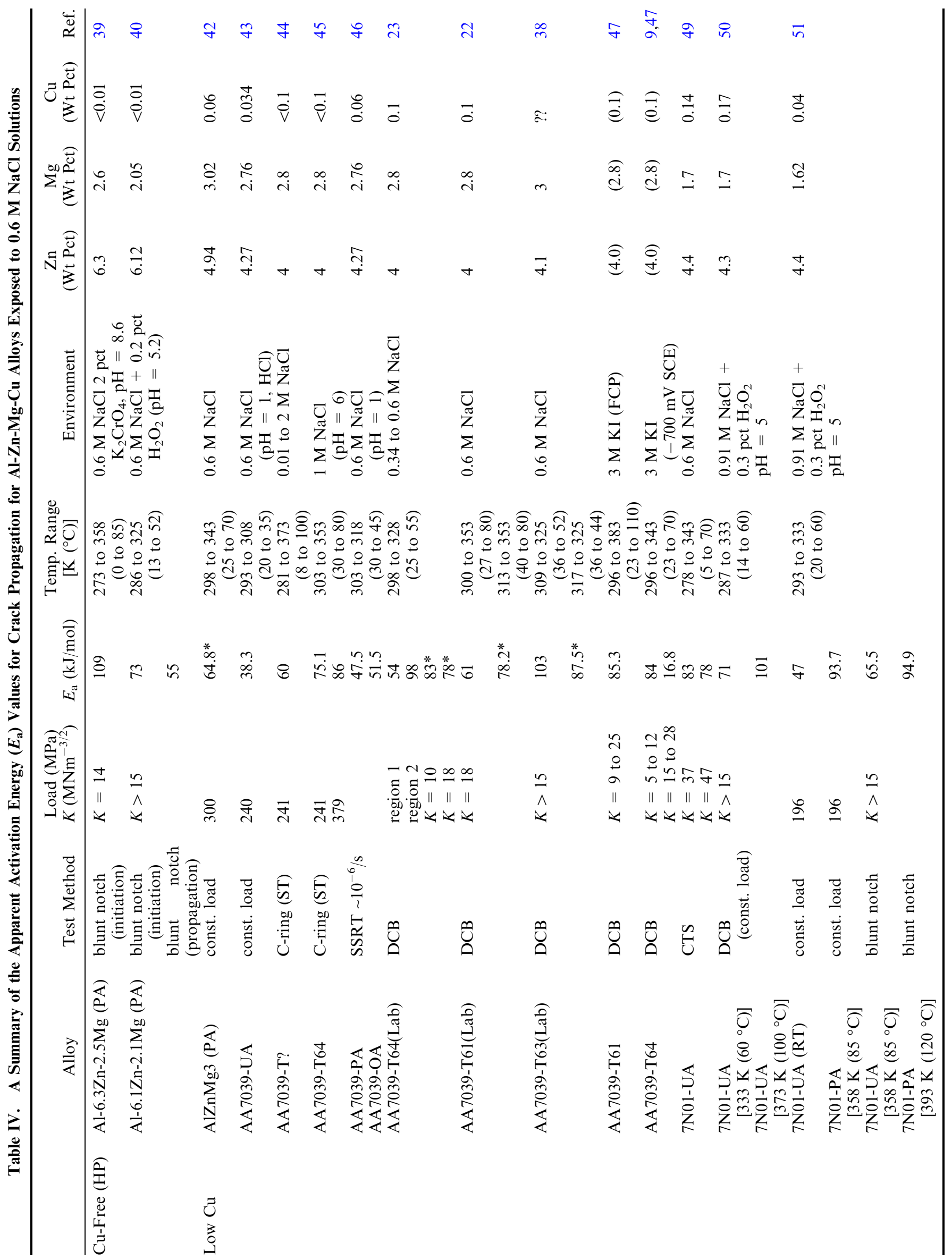




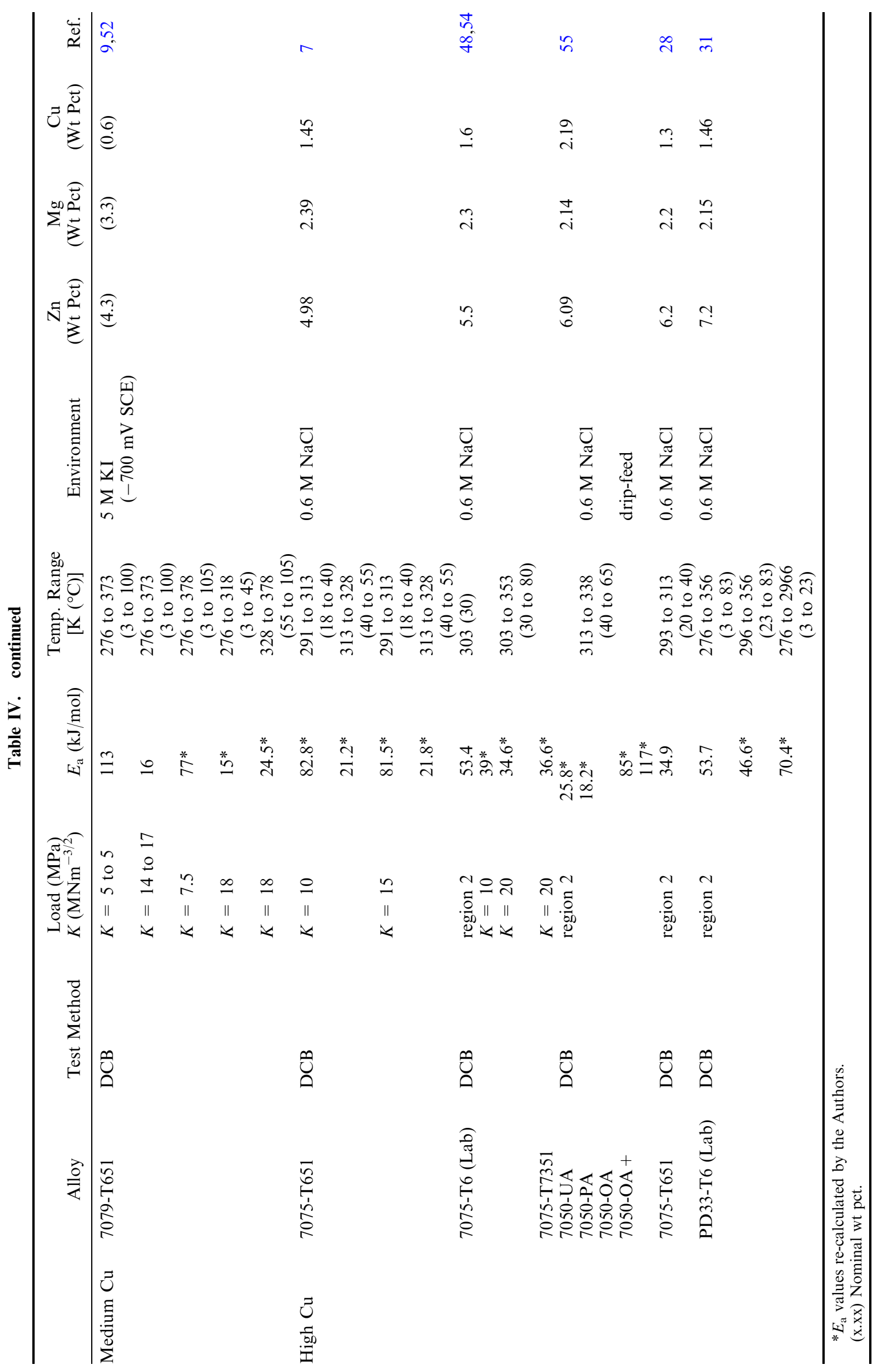



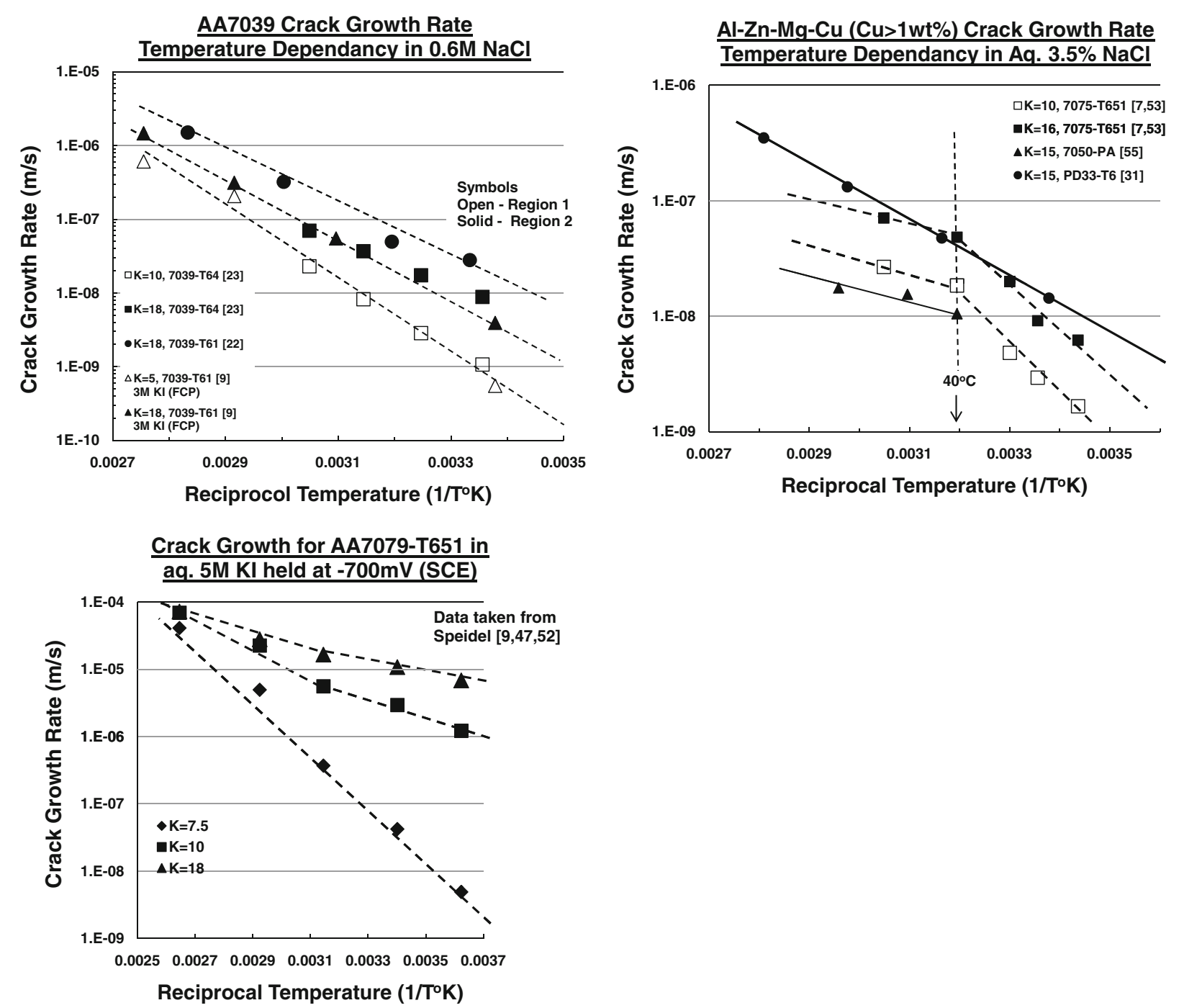

Fig. 8 - SCC growth rate from the literature for low-copper ${ }^{[9,22,23]}$ - and high-copper ${ }^{[7,31,53,55]}$-containing Al-Zn-Mg-Cu alloys exposed to an aqueous $0.6 \mathrm{M} \mathrm{NaCl}$ solution and for AA7079-T651(medium-copper-containing alloy) exposed to an aqueous $5 \mathrm{M}$ KI solution while under anodic polarization at $-700 \mathrm{mV}$ (SCE) ${ }^{[9,47,52]}$

For higher-copper-containing alloys, data are limited to that provided for AA7050 by Bovard, ${ }^{[55]}$ and for AA7075 by Onoro and Ranninger. ${ }^{[48]} E_{\mathrm{a}}$ values for AA7050 under region 2 loading conditions $\left(K>15 \mathrm{MNm}^{-3 / 2}\right)$ at temperatures greater than $313 \mathrm{~K}\left(40{ }^{\circ} \mathrm{C}\right)$ remain at around $20 \mathrm{~kJ} / \mathrm{mol}$ for under- and peak-aged tempers, but significantly increase up to $\sim 85 \mathrm{~kJ} / \mathrm{mol}$ with over-aging, Table IV. The $E_{\mathrm{a}}$ value of around $35 \mathrm{~kJ} / \mathrm{mol}$ quoted by Onoro and Ranninger ${ }^{[48]}$ for over-aged AA7075 at temperatures greater than $313 \mathrm{~K}\left(30^{\circ} \mathrm{C}\right)$ may not be reliable, because their crack propagation rates used in their calculations for a T7351 temper are an order of magnitude higher than those typically observed, Table III. This most likely because the alloys they tested were in an under-aged condition, resulting from the laboratory heat treatment of DCB test specimens, rather than the bulk plate material, which resulted in a higher high quench rate after solution heat treatment, with the aging treatment used being insufficient to achieve the preferred over-aged condition.
An overview of the SCC propagation apparent activation energy $\left(E_{\mathrm{a}}\right)$, as function of an alloy's copper content, for the peak-aged $\mathrm{Al}-\mathrm{Zn}-\mathrm{Mg}-\mathrm{Cu}$ alloys under region 2 loading conditions in the short-transverse plane $\left(K>15 \mathrm{MNm}^{-3 / 2}\right)$ when exposed to $0.6 \mathrm{M} \mathrm{NaCl}$ is shown in Figure 9.

\section{Local Solution Chemistry Within Pre-Cracks and Propagating Stress Corrosion Cracks}

SCC growth from a fatigue pre-crack is clearly a complicated process that is not well understood. It is probable that when a sodium chloride solution is introduced into a fatigue pre-crack, the local chloride ion concentration decreases because of chloride ion uptake by the alumina film on the fatigue pre-crack's surfaces. ${ }^{[57-62]}$ This is supported by experimental observations that have demonstrated that local chloride ion depletion occurs within tight crevices ${ }^{[63]}$ and SCC-tip regions, ${ }^{[64,65]}$ as shown in Figure 10, and chloride ion uptake by alumina 


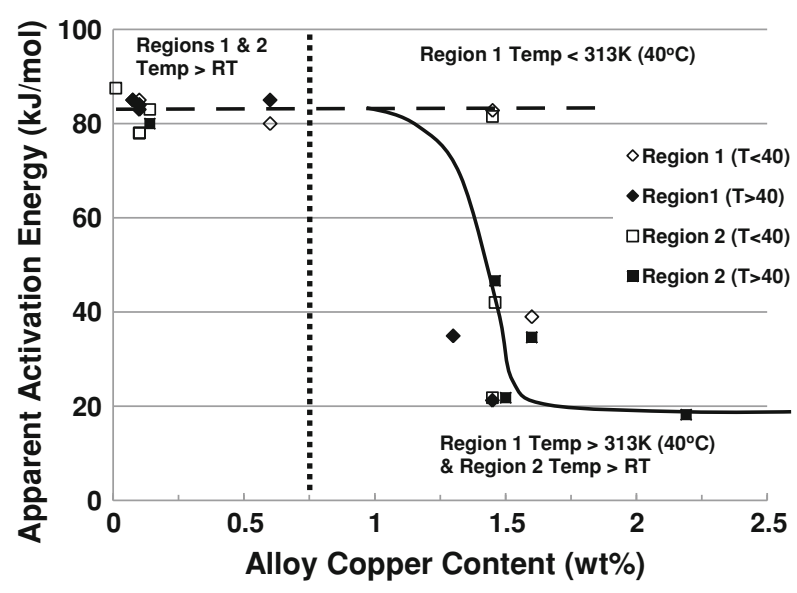

Fig. 9-SCC propagation apparent activation energy $\left(E_{\mathrm{a}}\right)$ as a function of alloy's copper content for peak-aged $\mathrm{Al}-\mathrm{Zn}-\mathrm{Mg}-\mathrm{X}$ pct. $\mathrm{Cu}$ alloys in $0.6 \mathrm{M}$ sodium chloride solution, using data quoted in Table IV.

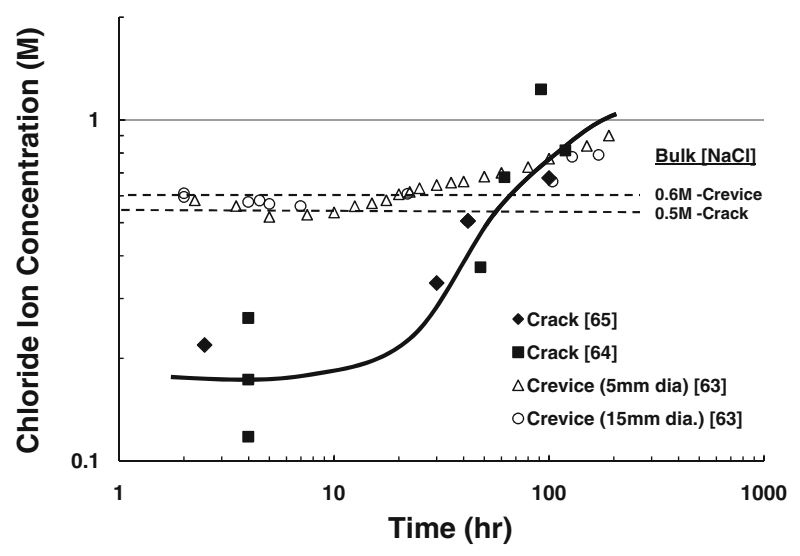

Fig. 10-Local chloride ion concentration within crevice and crack geometries for AA7475-T651 exposed to 0.5 through $0.6 \mathrm{M} \mathrm{NaCl}$ solutions.

or aluminum alloy surfaces exposed to saline solutions, ${ }^{[57-62]}$ as shown in Figure 11. It is also significant that the initial crack growth rates from fatigue precracked $\mathrm{Al}-\mathrm{Zn}-\mathrm{Mg}-\mathrm{Cu}$ alloys exposed to saline solutions are the same as those reported in distilled water.

Chloride ion depletion is exacerbated in confined crack and crevice geometries where there is a high oxide surface area-to-solution volume ratio and the oxide surfaces totally deplete the chloride concentration. The predicted lengths for total chloride ion depletion behind the crack-tip of a $2-\mathrm{mm}$ fatigue pre-crack in a conventional DCB specimens, ${ }^{[5,66]}$ exposed to sodium chloride solutions and loaded to various stress intensity factors are shown in Figure 12, using the chloride surface uptake data for alumina from Figure 11 and assuming that the pre-crack geometry may be represented by a trapezoidal region ${ }^{[67,68]}$ with its dimensional dependency upon the applied stress intensity factor described by a relationship developed by Mostovoy et al. ${ }^{[69]}$

The chloride ion uptake by the alumina surfaces covering a 2-mm fatigue pre-crack may be estimated

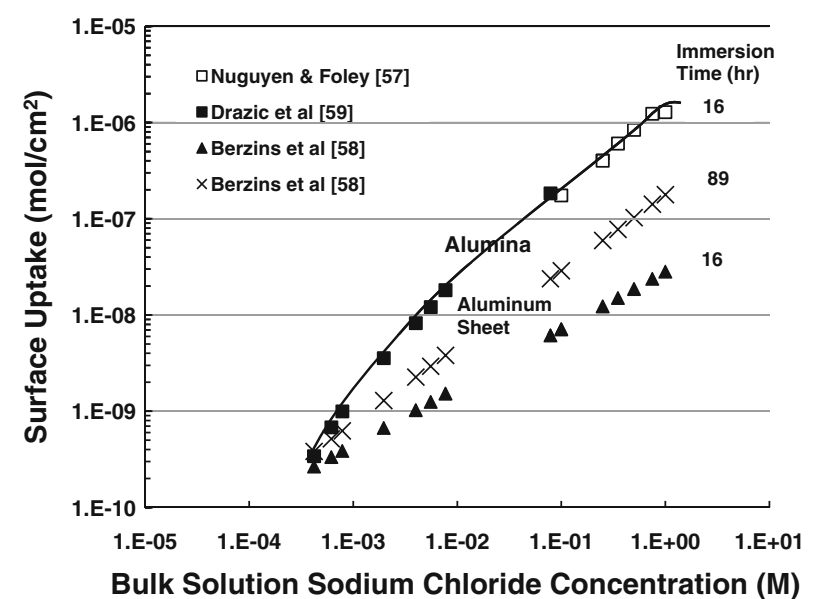

Fig. 11-Chloride ion uptake by alumina and pure aluminum surfaces following exposure to sodium chloride solutions of various concentrations.

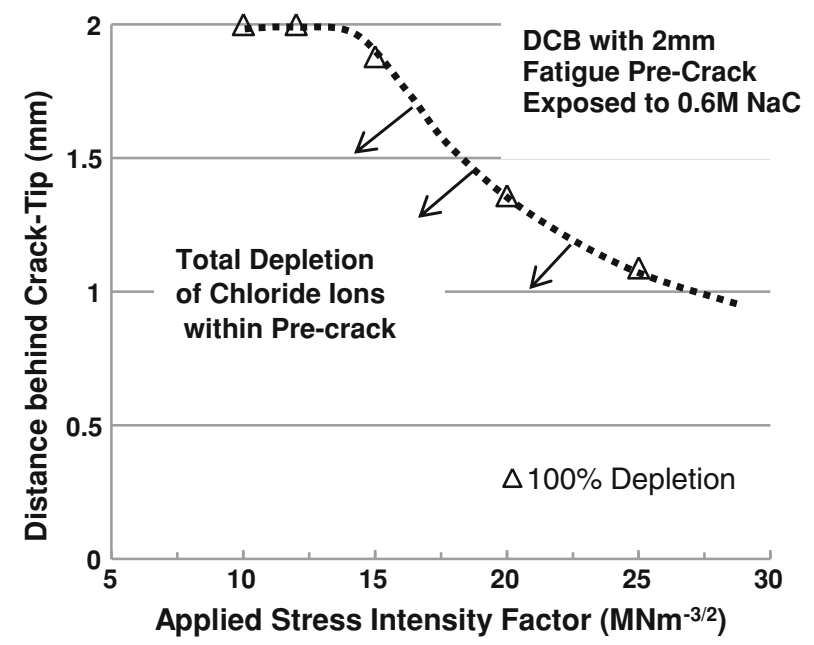

Fig. 12-Predicted length of chloride ion depletion in a 2-mm fatigue pre-crack in a conventional DCB specimen ${ }^{[5,66]}$ loaded to various stress intensity factors.

using, the measured chloride ion concentration obtained from $5 \mu \mathrm{L}$ samples taken from the crack-tip region ${ }^{[64,65]}$ (Figure 10) and published chloride ion-alumina adsorption data ${ }^{[57-62]}$ combined with estimated local solution volumes, again assuming a trapezoidal crack geometry ${ }^{[67,68]}$ with a dimensional dependency upon the applied stress intensity factor as described by the relationship provided by Smith and Piper. ${ }^{[70]}$

The estimated solution volume within a $2-\mathrm{mm}$ precrack loaded to $K=20 \mathrm{MNm}^{-3 / 2}$ is $1.65 \mu \mathrm{L}$ and the measured chloride ion concentration of $0.2 \mathrm{M}$ from $5 \mu \mathrm{L}$ test samples taken during the initial stages of testing (Figure 10) suggest that $0.33 \mathrm{M}$ had been depleted from the crack-tip region. If the $5 \mu \mathrm{L}$ sample had successfully removed all the solution from within the $2-\mathrm{mm}$ fatigue crack, then the remaining $\sim 3.35 \mu \mathrm{L}$ of the test sample would have come from the notch region above the crack. The total surface area of alumina associated with the $5 \mu \mathrm{L}$ sample would have been $5 \times 10^{-5} \mathrm{~m}^{2}$ for the crack and $2.7 \times 10^{-7} \mathrm{~m}^{2}$ for the 


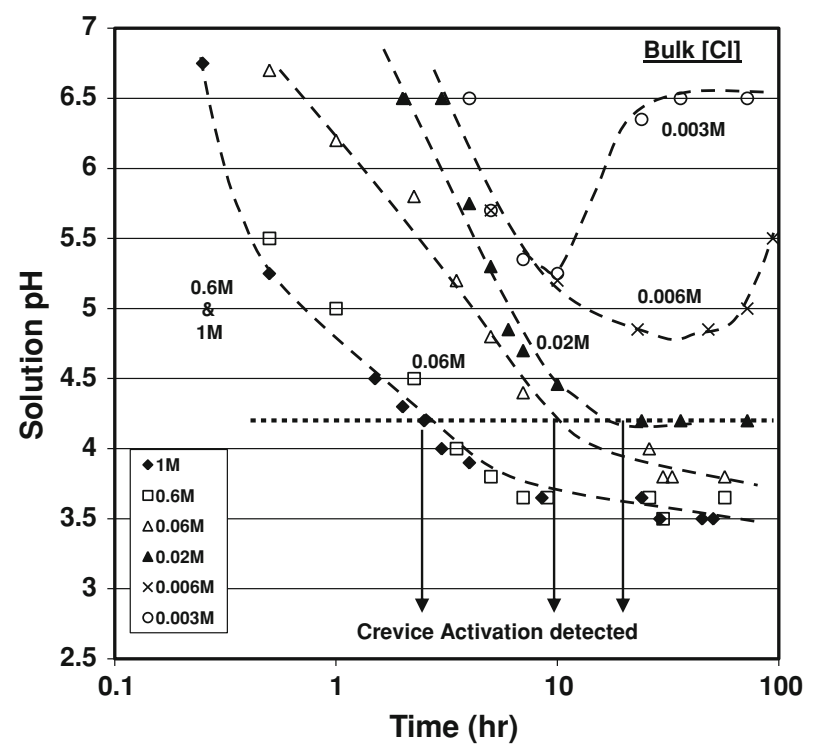

Fig. 13 - Local solution $\mathrm{pH}$ at the base of a tight crevice for AA7475T651 exposed to various aqueous sodium chloride solutions. ${ }^{[63]}$

notch region with an implied chloride ion surface uptake of $3.3 \times 10^{-7} \mathrm{~mol} / \mathrm{cm}^{2}$, which is in good agreement with the surface uptake data provided in Figure 11.

Nguyen and Foley's ${ }^{[57]}$ study of alumina exposure to aqueous sodium chloride solutions showed that the removal of chloride ions from the test solution was accompanied by the addition of dissolved aluminum species to the aqueous solution. Using their published data, the maximum concentration of dissolved aluminum species potentially introduced into the pre-crack resulting from interactions with the alumina surfaces could be as high as $0.0044 \mathrm{M}$, which using the chemical equilibrium reaction shown in Eq. [1], could generate a local solution $\mathrm{pH}$ of $\sim 3.8$, which is in good agreement with the experimental findings. ${ }^{[64,65]}$

It is reasonable to conclude that, following the adsorption of chloride ions onto the oxide surfaces covering a fatigue pre-crack, hydration and chemical reactivity (when a sufficient supply of chloride ions is available) will lead to generation of a gel-like surface film and a local aqueous environment containing oxy-chloride species, such as $\mathrm{Al}(\mathrm{OH})_{2} \mathrm{Cl}$ and $\mathrm{Al}(\mathrm{OH}) \mathrm{Cl}_{2},{ }^{[71-75]}$ with a $\mathrm{pH}$ less than 4 controlled by the equilibrium process:

$$
\mathrm{Al}^{3+}+\mathrm{H}_{2} \mathrm{O} \leftrightarrow \mathrm{AlOH}^{2+}+\mathrm{H}^{+}
$$

Experimental support of this behavior is provided by

(a) Wong and Alkire's ${ }^{[71]}$ characterization of local environments developing within naturally occurring 100 -micron deep pits in pure aluminum exposed to $1 \mathrm{M} \mathrm{NaCl}$, suggesting that the prominent chemical species within pits are $\mathrm{Al}(\mathrm{OH}) \mathrm{Cl}_{2}$ and/or $\mathrm{Al}(\mathrm{OH})_{2} \mathrm{Cl}$ (using nuclear resonance magnetic spectroscopy) with the local solution of $\mathrm{pH} 3$ through 4 ,

(b) Holroyd and Jarrett's ${ }^{[63]}$ local solution $\mathrm{pH}$ measurements at the base of an artificial split-crevice

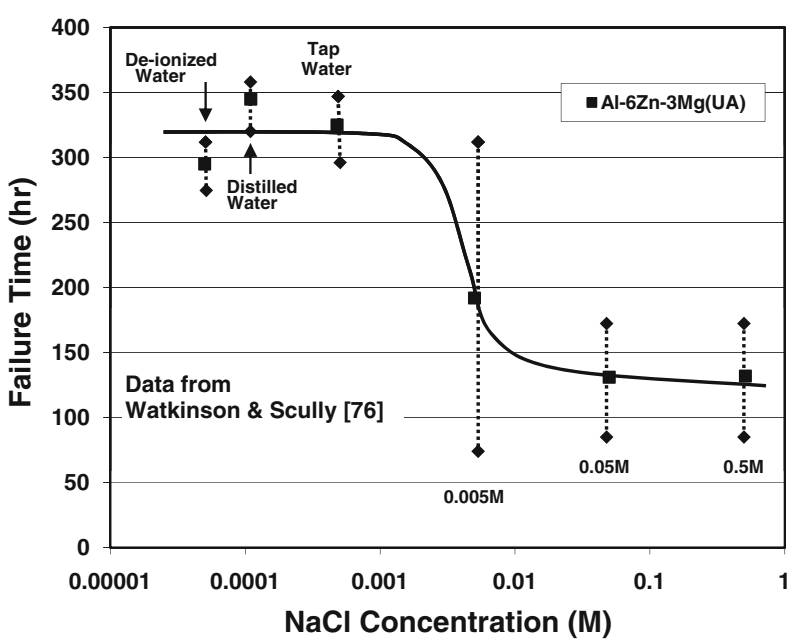

Fig. 14-Influence of the bulk sodium chloride concentration on the $\mathrm{SCC}$ of an under-aged high-purity $\mathrm{Al}-\mathrm{Zn}-\mathrm{Mg}$ alloy in saline solutions. ${ }^{[76]}$

AA7075-T651 ReRegion $2\left(\mathrm{~K}=15 \mathrm{MNm}^{-3 / 2}\right) \mathrm{SCC}$ in Aq. Saline Solutions

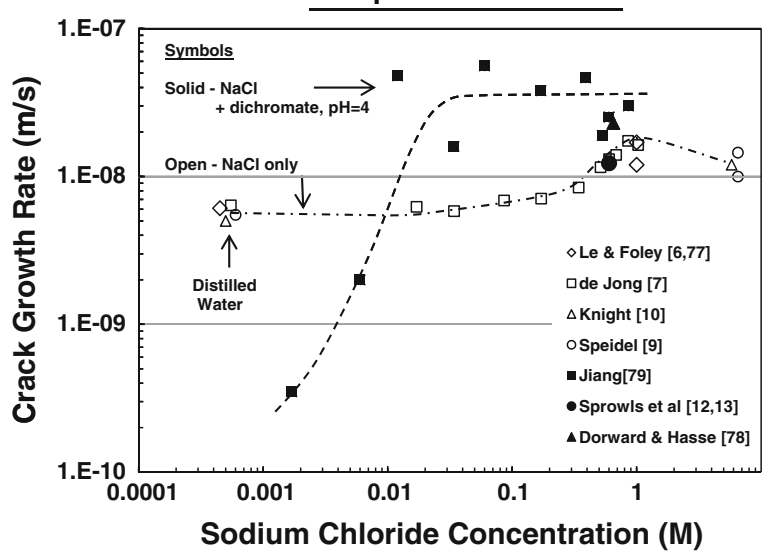

Fig. 15-Influence of bulk solution sodium chloride concentration on the region $2\left(K=15 \mathrm{MNm}^{-3 / 2}\right)$ crack growth rate for AA7075T651 in aqueous solutions containing $0.6 \mathrm{M} \mathrm{NaCl}$ (de Jong ${ }^{[7]}$ data at $291 \mathrm{~K}\left(18{ }^{\circ} \mathrm{C}\right)$ adjusted to $298 \mathrm{~K}\left(25^{\circ} \mathrm{C}\right)$, using appropriate apparent activation energy, $E_{\mathrm{a}}$, data).

for AA7475-T651 exposed to various aqueous sodium chloride solutions, Figure 13, indicating that a bulk solution sodium chloride concentration greater than $\sim 0.01 \mathrm{M}$ is required for the local solution to maintain a stable $\mathrm{pH}$ less than 4 and

(c) Kolics et al. ${ }^{[61]}$ observations, based on X-ray photoelectron spectroscopy results that, surface films formed on pure aluminum exposed to aqueous $0.1 \mathrm{M} \mathrm{NaCl}$ solutions with pH's less than 10 are the thickest for solution $\mathrm{pHs}$ of around 3.8, with chloride species within this film being concentrated in the outer $25 \AA$ of the $\sim 68 \AA$-thick film and that the film thickness and its chloride content drop suddenly and sharply as solution $\mathrm{pH}$ falls from $\sim 3.8$ to 3 , undergoing a 50 pct reduction in both thickness and chloride content. 


\section{EFFECT OF BULK SOLUTION CHLORIDE CONCENTRATION AND PRESENCE OF CHROMATE SPECIES ON CRACK GROWTH BEHAVIOR}

\section{A. Influence of Chloride Ion Concentration in Absence of Other Additions}

Watkinson and Scully ${ }^{[76]}$ conducted a series of U-bend SCC tests on an under-aged high-purity Al-6Zn-3Mg alloy exposed to various aqueous sodium chloride solutions in closed beakers, limiting the availability of oxygen during testing. As shown in Figure 14, it is clear that cracks initiate and grow irrespective of the bulk chloride concentration and that SCC susceptibility increases significantly when sodium chloride concentrations exceed around $0.01 \mathrm{M}$, but increases only marginally with further increase of chloride concentration.

Information quantifying the influence of bulk solution chloride ion concentration on the SCC growth characteristics for $\mathrm{Al}-\mathrm{Zn}-\mathrm{Mg}-\mathrm{Cu}$ alloys is limited to that available for AA7079-T651 ${ }^{[26]}$ and AA7075-T651. ${ }^{[6,7,77]}$ For AA7079-T651, region 2 crack growth rates were insensitive to bulk solution $\mathrm{NaCl}$ concentrations ranging from 0.05 through $6 \mathrm{M}$. For AA7075-T651, results are consistent with a minimum chloride concentration of around $0.01 \mathrm{M}$ being required for crack growth rates to exceed those generated in distilled water. Crack growth rates slowly increase with chloride concentration up to around $0.6 \mathrm{M}$, greater than which, they slightly decrease, Figure 15, presumably associated with a lower dissolved oxygen levels and/or a lower water activity (reduced availability of free water). ${ }^{[20]}$

More information is available on the effect of bulk chloride concentration on region 2 crack growth rates for AA7075-T651 immersed in an inhibited-acidified saline solution $\quad\left[0.02 \mathrm{M} \quad \mathrm{Na}_{2} \mathrm{Cr}_{2} \mathrm{O}_{7}+0.07 \mathrm{M} \quad \mathrm{CH}_{3} \mathrm{COONa}\right.$, $\mathrm{pH}=4$ (acetic acid)]. ${ }^{[12,78-80]}$ Information obtained by analyzing crack length-time data provided by Jiang ${ }^{[79]}$ for chloride ion concentrations ranging from 0.0017 to $0.86 \mathrm{M}$, Table $\mathrm{V}$, is also included in Figure 15.

\section{B. SCC in Acidified-Inhibited Saline Solutions}

The development of a buffered-acidified-inhibited saline SCC test environment to minimize general corrosion dates back to the early 1970 s. ${ }^{[12]}$ This study was successful as both the general corrosion and post-fracture corrosion of SCC surfaces were minimized, and region 2 crack growth rates were equivalent or higher for both low- ${ }^{[38]}$ and high- ${ }^{[78]}$ copper-containing Al-Zn-Mg-Cu alloys compared with crack growth rates obtained in a $0.6 \mathrm{M} \mathrm{NaCl}$ solution without any additions.

However, the introduction of dichromate or chromate ions significantly increased crack initiation times, even when the environment was acidified and buffered to a $\mathrm{pH}$ of 4. An excellent example of this is the SCC growth measurements of Landkof and Gal-Or ${ }^{[38]}$ for a lowcopper-containing Al-Zn-Mg-Cu alloy, AA7039, in $0.6 \mathrm{M} \mathrm{NaCl}$ solution with and without a sodium dichromate addition, as shown in Figure 16. Interestingly while the crack initiation times are considerable longer with the dichromate addition, $120 \mathrm{~h}$, compared with $14 \mathrm{~h}$ without the addition, the region 2 crack growth rates are significantly higher for test solution containing the dichromate addition, Figure 16.

Detailed experimental measurements characterizing the influence of bulk solution sodium chloride concentration on crack initiation times and subsequent SCC growth behavior for $\mathrm{Al}-\mathrm{Zn}-\mathrm{Mg}-\mathrm{Cu}$ alloys immersed in saline solutions as a function of the initially applied stress intensity factor is currently only available for sodium chloride solutions also containing $0.02 \mathrm{M}$ sodium dichromate and $0.07 \mathrm{M}$ sodium acetate additions with their pHs adjusted to 4 using acetic acid.

The presence of the dichromate ion hinders local chemical reactivity within restricted geometries by competitively adsorbing along with chloride ions onto the air-formed films, which extend the times required for the development of acidified local environmental conditions and the complex aluminum and chloride species that activate both crevices and crack-tip regions.

The SCC length-time results for fatigue pre-cracked test specimens of AA7075-T651, ${ }^{[12,13,79,80]}$ AA7075T7351 ${ }^{78]}$ and AA7040-T7651 ${ }^{[36,81]}$ cracking in an acidified inhibited saline solution ${ }^{[12,66]}$ show several examples where the initial crack growth rates are 5 to 10 times slower than subsequent growth rates. A typical example is provided in Figure 17, for AA7075-T651 loaded to an initial $K$ of $9.6 \mathrm{MNm}^{-3 / 2}$ and exposed to acidified inhibited saline solution at room temperature, with subsequent crack growth characteristics given in Table $\mathrm{V}$.

Our analysis of Jiang ${ }^{[79]}$ and Zhang et al.' ${ }^{[80]}$ crack growth measurements for AA7075-T651 under various loading conditions in acidified inhibited saline solutions show that SCC crack initiation and growth from fatigue pre-cracked test specimens is relatively insensitive to bulk sodium chloride concentration greater than $0.01 \mathrm{M}$ and up to at least $0.86 \mathrm{M}$, Figure 15. As shown in Figure 18 cracks initiate after an incubation time, which decreases with increasing applied stress intensity and then propagate at a rate similar to that observed in distilled water, ${ }^{[9]}$ Figure 19, and then after a time, which also decreases with increasing applied stress intensity, ${ }^{[82]}$ accelerate to a 5 to 10 times faster growth rate, Figure 19.

When bulk sodium chloride concentrations are less than $0.01 \mathrm{M}$, initial crack growth rates no longer increase after an incubation period and crack growth rates remain similar to those reported in distilled water, ${ }^{[9]}$ unless bulk sodium chloride concentrations are extremely low, e.g., less than $0.005 \mathrm{M}$, where the inhibitor addition further reduces the crack growth rate, Figure 20.

Crack growth rate increases have been observed during the DCB stress corrosion testing of low-coppercontaining, AA7039-T63 (Figure 16) and high-coppercontaining Al-Zn-Mg-Cu alloys, in peak- (Figure 17) and over-aged (Figure 2) tempers. Initial crack growth rates are similar to those observed in distilled water, and the incubation time required for faster crack growth in high copper-containing alloys increases significantly with over-aging, Table VI.

Over the last decade, detailed experimental studies at the University of Virginia, ${ }^{[83-88]}$ have characterized the 
Table V. SCC Crack Growth Characteristics at Room Temperature Calculated from Crack Length-Time Data Provided by Jiang $^{179]}$ for AA7075-T651 Fatigue Pre-Cracked Compact Tension Specimens Loaded to Various Initial Stress Intensity Factors and Exposed to in an Acidified Inhibited Saline Solution Containing Various Chloride Concentrations, 0.0017 through $0.86 \mathrm{M}$ Along with $0.02 \mathrm{M}$ Sodium Dichromate and $0.07 \mathrm{M}$ Sodium Acetate, acidified to $\mathrm{pH}=4$

\begin{tabular}{|c|c|c|c|c|c|c|c|c|}
\hline \multirow[b]{3}{*}{$\mathrm{NaCl}(\mathrm{M})$} & \multicolumn{5}{|c|}{ Initial Crack Growth from Pre-Crack } & \multicolumn{3}{|c|}{ Region 2 Crack Growth } \\
\hline & \multirow[b]{2}{*}{$\begin{array}{l}\text { Initiation } \\
\text { Time }(\mathrm{h})\end{array}$} & \multirow[b]{2}{*}{$\frac{\mathrm{K}}{\left(\mathrm{MNm}^{-3 / 2}\right)}$} & \multicolumn{3}{|c|}{ Slow Crack Growth } & \multirow[b]{2}{*}{$K\left(\mathrm{MNm}^{-3 / 2}\right)$} & \multirow[b]{2}{*}{$\mathrm{CV}(\mathrm{m} / \mathrm{s})$} & \multirow[b]{2}{*}{$\begin{array}{c}\text { Growth } \\
(\mathrm{mm})\end{array}$} \\
\hline & & & $\begin{array}{l}\text { Distance } \\
(\mathrm{mm})\end{array}$ & $\begin{array}{l}\text { Time } \\
\text { (h) }\end{array}$ & $\mathrm{CV}(\mathrm{m} / \mathrm{s})$ & & & \\
\hline \multirow[t]{5}{*}{0.0017} & 600 & 8.0 & 0.5 & 3140 & $5.9 \times 10^{-11}$ & 9.0 to 19.0 & $2.1 \times 10^{-10}$ & 1.2 \\
\hline & 510 & 10.2 & 0.35 & 1480 & $1.0 \times 10^{-10}$ & 10.2 to 11.9 & $3.5 \times 10^{-10}$ & 2.4 \\
\hline & 497 & 10.2 & 1.5 & & $2.2 \times 10^{-10}$ & 10.2 to 10.8 & & 1.5 \\
\hline & 350 & 12.1 & 5.2 & & $3.8 \times 10^{-10}$ & 12.1 to 14.1 & & 5.2 \\
\hline & 310 & 14.9 & 6.2 & & $5.8 \times 10^{-10}$ & 14.9 to 20.7 & & 6.2 \\
\hline \multirow[t]{6}{*}{0.006} & 210 & 6 & 0.4 & 550 & $2.4 \times 10^{-10}$ & 8.34 & $1.3 \times 10^{-9}$ & 0.6 \\
\hline & - & - & - & 591 & - & 14 to 15.9 & $5.6 \times 10^{-9}$ & 1.6 \\
\hline & 83 & 10.4 & 1.26 & 740 & $5.3 \times 10^{-10}$ & 10.8 to 26.5 & $1.7 \times 10^{-9}$ & 12.1 \\
\hline & 60 & 12.1 & 0.4 & 360 & $3.8 \times 10^{-10}$ & 12.0 to 15.2 & $1.7 \times 10^{-9}$ & 2.0 \\
\hline & 125 & 14.5 & 15.2 & & $2.8 \times 10^{-9}$ & 14.5 to 20 & & \\
\hline & 50 & 14.9 & 2.0 & & $2.0 \times 10^{-9}$ & 14.9 to 17.5 & & \\
\hline 0.012 & 50 & 10 & 2.0 & 250 & $2.4 \times 10^{-9}$ & 11.5 to 22.6 & $2.4 \times 10^{-8}$ & 14.2 \\
\hline 0.017 & 30 & 10.2 & 2.2 & 145 & $4.8 \times 10^{-9}$ & 11.0 to 22.6 & $1.6 \times 10^{-8}$ & 8.5 \\
\hline \multirow[t]{6}{*}{0.06} & 154 & 5.7 & 0.6 & 245 & $1.9 \times 10^{-9}$ & 8.2 to 15.8 & $2.06 \times 10^{-8}$ & 6.1 \\
\hline & 30 & 8.1 & 1.1 & 270 & $1.3 \times 10^{-9}$ & 9.1 to 11.0 & $3.7 \times 10^{-8}$ & 10.0 \\
\hline & 20 & 10 & 1.6 & 145 & $3.5 \times 10^{-9}$ & 11.5 to 18.1 & $5.6 \times 10^{-8}$ & 10.5 \\
\hline & 20 & 12 & 1.8 & 185 & $2.7 \times 10^{-9}$ & 12.8 to 19.7 & $4.2 \times 10^{-8}$ & 8.9 \\
\hline & 20 & 14.31 & 1.5 & 135 & $3.6 \times 10^{-9}$ & 15.0 to 24.0 & $4.5 \times 10^{-8}$ & 10.0 \\
\hline & 19 & 14.9 & 1.1 & 90 & $3.8 \times 10^{-9}$ & 15.2 to 16.0 & $1.4 \times 10^{-8}$ & 1.5 \\
\hline \multirow[t]{2}{*}{0.17} & 40 & 10.0 & 0.4 & 125 & $2.2 \times 10^{-9}$ & 10.5 to 21.3 & $4.1 \times 10^{-8}$ & 12.5 \\
\hline & 18 & 14.6 & 0.9 & 40 & $2 \times 10^{-9}$ & 15.0 & $3.6 \times 10^{-8}$ & 1.4 \\
\hline 0.34 & 27 & 9.9 & 1.2 & 140 & $2.8 \times 10^{-9}$ & 11.3 to 29.3 & $4.65 \times 10^{-8}$ & 9.9 \\
\hline 0.53 & 45 & 10.1 & 0.6 & 125 & $2.1 \times 10^{-9}$ & 10.5 to 20.8 & $1.9 \times 10^{-8}$ & 10.5 \\
\hline \multirow[t]{8}{*}{0.60} & 91 & 5.8 & 0.9 & 273 & $1.4 \times 10^{-9}$ & 5.9 to 13.0 & $1.9 \times 10^{-8}$ & 13.1 \\
\hline & 108 & 6.5 & 3.5 & 490 & $1.4 \times 10^{-9}$ & 5.3 ( $\mathrm{K}$ decrease) & - & - \\
\hline & 36 & 8.0 & 2.1 & 205 & $3.5 \times 10^{-9}$ & 8.5 to 14 & $2.5 \times 10^{-8}$ & 14 \\
\hline & 26 & 9.6 & 0.6 & 99 & $2.1 \times 10^{-9}$ & 9.8 to 18.0 & $1.6 \times 10^{-8}$ & 3.7 \\
\hline & 22 & 9.9 & 0.6 & 120 & $1.7 \times 10^{-9}$ & 9.9 to 9.5 ( $\mathrm{K}$ decrease $)$ & $6.8 \times 10^{-9}$ & 4.7 \\
\hline & 54 & 9.9 & 0.15 & 85 & $1.4 \times 10^{-9}$ & 12 & $1.5 \times 10^{-8}$ & 3.7 \\
\hline & 20 & 12.2 & 0.6 & 86 & $2.4 \times 10^{-9}$ & 12.5 to 18 & $2.1 \times 10^{-8}$ & 8.6 \\
\hline & 15 & 16 & 0.5 & 50 & $3.8 \times 10^{-9}$ & 16.5 to 18.4 & $1.7 \times 10^{-8}$ & 3.7 \\
\hline 0.86 & 60 & 10.0 & 1.0 & 160 & $3.1 \times 10^{-9}$ & 11.0 to 30.0 & $3.0 \times 10^{-8}$ & 15.3 \\
\hline
\end{tabular}

local environmental conditions associated with region 2 SCC growth in pre-cracked anodized AA7050 WOL specimens exposed to an inhibited saline environment with a high chromate $\left(0.5 \mathrm{M} \mathrm{Na}_{2} \mathrm{CrO}_{4}\right)$ and a low chloride ion concentration $(0.05 \mathrm{M} \mathrm{NaCl})$ at its natural $\mathrm{pH}$ of 9.2. These studies included real-time monitoring of the local crack-tip environment during crack growth, using micro-electrodes $(\mathrm{pH}$, chloride and electrochemical potential) embedded in tests specimens that had been fatigue pre-cracked in the test environment, thereby avoiding the potential complications associated with chloride depletion due to adsorption by air-formed films on pre-crack surfaces. However, a significant local chloride ion depletion was detected during the initial stage of testing, with local chloride ion concentrations falling by at least $50 \mathrm{pct},{ }^{[86,87]}$ independent of any detectable effect on crack growth and conceivably because of the local crack-tip environment wetting the alumina surfaces on the mechanically drilled hole housing the chloride ion micro-electrode embedded in the WOL test specimen just ahead of the fatigue precrack.

A notable difference between the results obtained by the University of Virginia and that reported by others stems from their choice of a test environment, with its high chromate-to-low chloride ion ratio, restricting the promotion of crack growth rate enhancement to situations where sufficient external anodic polarization is applied, without which, crack growth rates remain similar or less than those promoted in distilled water, irrespective of the incubation time.

For AA7050-T6 exposed to the high chromate-low chloride solution, Young ${ }^{[83]}$ reported that region 2 crack growth rates $\left(K \sim 14 \mathrm{MNm}^{-3 / 2}\right)$ were: around $2 \times 10^{-10} \mathrm{~m} / \mathrm{s}$ at the free corrosion potential of $-850 \mathrm{mV}$ (SCE), and then remained low with increasing external anodic polarization up to around $-500 \mathrm{mV}$ (SCE), but greater than a critical potential of $-495 \mathrm{mV}$ (SCE) increased suddenly after an incubation period, which at $-495 \mathrm{mV}$ (SCE) was $\sim 17 \mathrm{~h}$. Cooper and 


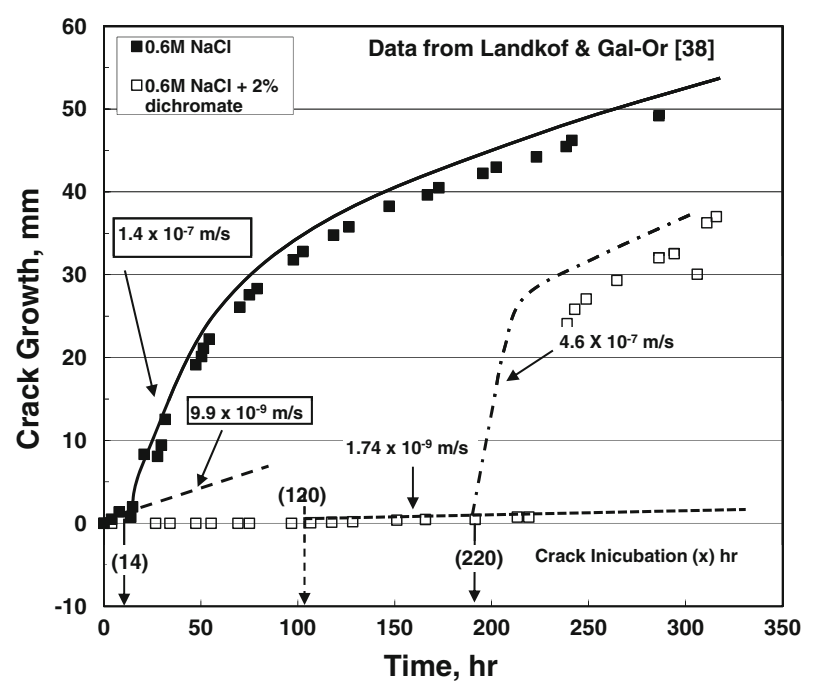

Fig. 16 - Crack growth at $303 \mathrm{~K}\left(30^{\circ} \mathrm{C}\right)$ during DCB SCC testing AA7039-T63 in an aqueous $0.6 \mathrm{M}$ sodium chloride solution with and without a 2 pct sodium dichromate addition. Data taken from Landkof and Gal-Or. ${ }^{[38]}$

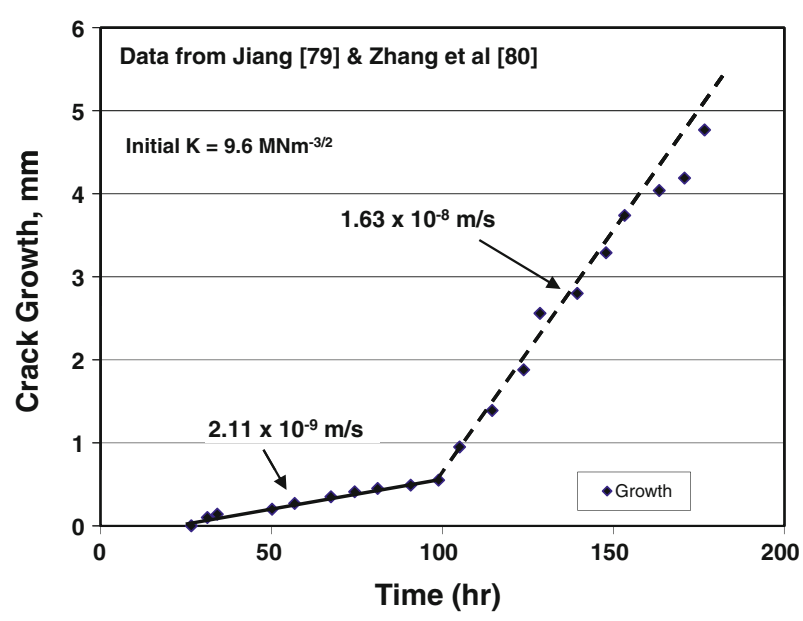

Fig. 17-Typical SCC growth from fatigue pre-cracked AA7075T651 specimens exposed to an acidified-inhibited saline solution.

Kelly ${ }^{[86,87]}$ characterized the local environmental conditions developing within propagating SCC-tip region, before, during and post the onset of the accelerated crack growth rate. Incubation periods, depending on the applied anodic potential and alloy temper, ranged from a few hours up to several days. Their findings show that the environmental conditions in the crack-tip region (solution $\mathrm{pH}$, chloride ion concentration and electrochemical potential) during the incubation period remain similar to those of the bulk solution, with crack growth rates corresponding to those reported in distilled water and then several hours before the onset of accelerated crack growth, the electrochemical potential in the cracktip region showed repeated activation and re-passivation, accompanied by the local chloride ion concentration increasing from $0.05 \mathrm{M}$ (the bulk concentration) to a maximum of around $0.5 \mathrm{M}$, coincident with a small decrease in the crack region electrochemical potential

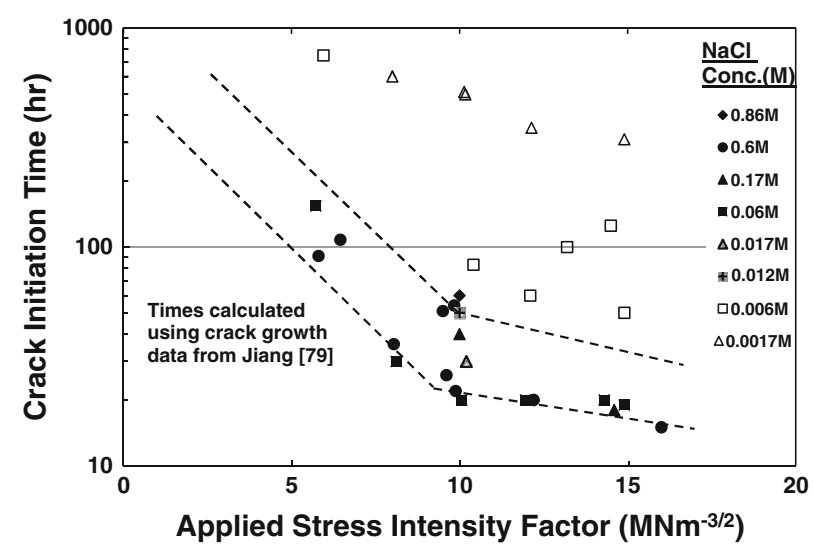

Fig. 18 - Crack initiation times for fatigue pre-cracked AA7075-T651 specimens loaded to various initial stress intensity factors and exposed to an acidified inhibited saline solution containing a range of sodium chloride concentrations, 0.0017 to $0.6 \mathrm{M}$.

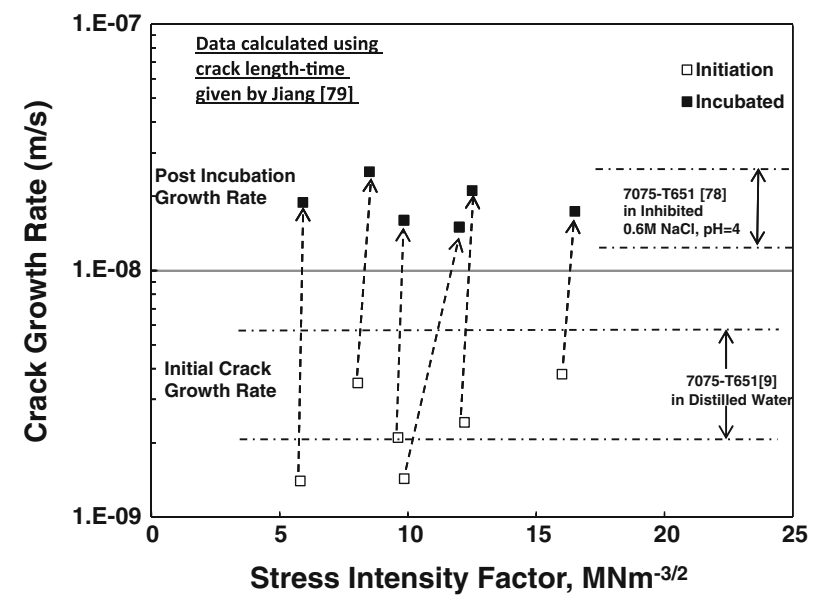

Fig. 19-Initial and region 2 SCC growth rates for fatigue precracked specimens loaded to various initial stress intensity factors in an acidified inhibited saline solution containing $0.6 \mathrm{M} \mathrm{NaCl}+0.02$ $\mathrm{M} \mathrm{Na}_{2} \mathrm{Cr}_{2} \mathrm{O}_{7}+0.07 \mathrm{M} \mathrm{CH}_{3} \mathrm{COONa}, \mathrm{pH}=4$.

$(\sim 35 \mathrm{mV})$ just before depolarization. Finally the onset of acidification of the local environment, occurred over a period of several hours, accompanied by an increasing crack growth rate, with its maximum rate and the cracktip region's solution $\mathrm{pH}$ being dictated by the externally applied anodic potential, Table VII, Figure 21.

\section{SCC Initiation from Fatigue and Mechanical "Pop-in" Starter Cracks}

Dorward and Hasse ${ }^{[34,78]}$ reported SCC length-time data for a series of high-copper-containing alloys in a well over-aged condition (T7351). This study showed that crack initiation times were significantly longer for DCB test specimens with fatigue pre-cracks, as compared with mechanical "pop-in" starter cracks as shown in Table VIII. Dorward and Hasse ${ }^{[78]}$ considered that these longer times were due to a predominantly transgranular starter crack having to transition to an intergranular crack path, either by transgranular SCC 
or a mixed mode fracture process of intergranular SCC with mechanical rupture of remaining ligaments. It is interesting that having initiated, crack growth from a fatigue pre-crack propagates for around $1.5 \mathrm{~mm}$ at a low crack growth rate, similar to that observed in distilled water, before accelerating by a factor of around 8 to a growth rate similar to that established almost immediately for crack growth from mechanical "popin" pre-cracks, Figure 22.

It is highly probable that enhanced crack growth rates, are triggered by the local environmental changes occurring within the crack-tip region, that require time for these changes to exert a direct influence on the alloy

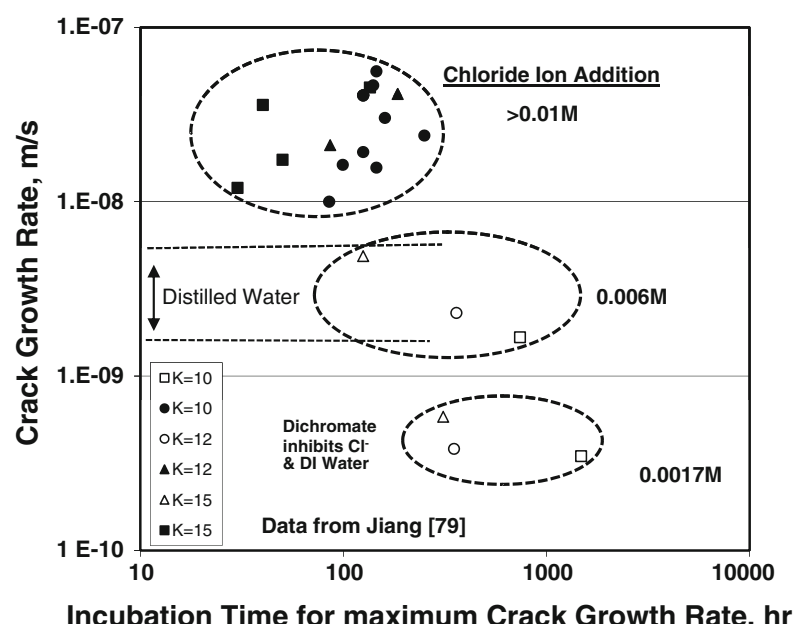

Fig. 20-Maximum SCC growth rates calculated from crack lengthtime data reported by Jiang ${ }^{[79]}$ for AA7075-T651 fatigue pre-cracked CTS specimens loaded to various stress intensity factors and immersed in an acidified-inhibited saline solution containing a range of sodium chloride additions (open symbols - initial crack growth rates, solid symbols - stage 2 crack growth rates). microstructure ahead of the crack to promote crack acceleration.

\section{DISCUSSION}

\section{A. Local Environmental Conditions Developing in Propagating Stress Corrosion Cracks}

The sequence of events occurring within the crackenclave region for a fatigue pre-cracked $\mathrm{Al}-\mathrm{Zn}-\mathrm{Mg}-\mathrm{Cu}$ alloy test specimen, subjected to region 2 loading and then immersed in a saline environment, are:

(a) Immediate uptake of chloride ions (and other ions such as chromate or dichromate) by exposed surfaces, including those in the pre-crack, that result in a significant local depletion of chloride ions in the crack-tip region,

(b) A time delay followed by crack initiation and slow crack growth independent of the presence of chloride ions at a rate equivalent to that for the alloy/ temper in distilled water,

(c) A period of slow crack growth, during which, if external conditions are appropriate (e.g., bulk chloride ion concentration and/or externally applied anodic potential), local environmental changes occur within the growing cracks, consisting of repeated activation and re-passivation of the crack-tip region, increasing local chloride ion concentration, a build-up of soluble aluminum species and a resultant acidification of the solution in the crack-tip region, followed by the triggering of,

(d) A sudden and significant increase of crack growth rate.

Although the time required to trigger accelerated crack growth rates under region 2 loading conditions are

Table VI. Influence of Alloy Temper on Crack Initiation Time, Slow Crack Growth, and Region 2 Crack Growth Rates for HighCopper-Containing Al-Zn-Mg-Cu Alloys Exposed to Various Saline Environments

\begin{tabular}{|c|c|c|c|c|c|c|c|}
\hline \multirow[b]{2}{*}{ Alloy [Ref] } & \multirow[b]{2}{*}{ Test Environment } & \multirow{2}{*}{$\begin{array}{l}\text { Initial } \mathrm{K} \\
\left(\mathrm{MNm}^{-3 / 2}\right)\end{array}$} & \multirow{2}{*}{$\begin{array}{l}\text { Crack } \\
\text { Initiation } \\
\text { Time (h) }\end{array}$} & \multirow{2}{*}{$\begin{array}{l}\text { Time of } \\
\text { Slow Crack } \\
\text { Growth (h) }\end{array}$} & \multicolumn{3}{|c|}{ Crack Growth Rate (m/s) } \\
\hline & & & & & Initial & Distilled Water & Region 2 \\
\hline \multicolumn{8}{|l|}{ Peak-Aged } \\
\hline $7075-\mathrm{T} 651^{[6]}$ & $1 \mathrm{M} \mathrm{NaCl}$ & 20 & - & 6 & - & 2 to $5 \times 10^{-9[9]}$ & $1.4 \times 10^{-8}$ \\
\hline $7075-\mathrm{T} 651^{[79]}$ & A & 16 & 15 & 50 & $3.8 \times 10^{-9}$ & & $1.7 \times 10^{-8}$ \\
\hline $7075-\mathrm{T} 6^{[81]}$ & $\mathrm{B}$ & 16.5 & 10 & 25 & $5 \times 10^{-9}$ & & $1.3 \times 10^{-8}$ \\
\hline \multicolumn{8}{|l|}{ Mildly Over-Aged } \\
\hline 7075-T7651 & Distilled Water & & & & & $2 \times 10^{-10[47]}$ & \\
\hline $7040-\mathrm{T} 7651^{[36]}$ & A & 27 & $\sim 20$ & 216 & $2.1 \times 10^{-10}$ & & $1.8 \times 10^{-9}$ \\
\hline $7150-\mathrm{T} 7751^{[36]}$ & A & 23 & - & 330 & $1.4 \times 10^{-10}$ & & $1.2 \times 10^{-9}$ \\
\hline $7249-\mathrm{T} 76511^{[14]}$ & $0.6 \mathrm{M} \mathrm{NaCl}$ & & $<24$ & 1218 & $7.6 \times 10^{-10}$ & & $1.7 \times 10^{-9}$ \\
\hline $7039-\mathrm{T} 63^{[38]}$ & $0.6 \mathrm{M} \mathrm{NaCl}$ & & - & 14 & $9.9 \times 10^{-9}$ & $1.1 \times 10^{-8}$ & $1.4 \times 10^{-7}$ \\
\hline $7039-\mathrm{T} 63^{[38]}$ & $\mathrm{C}$ & & 120 & 220 & $1.7 \times 10^{-9}$ & & $4.6 \times 10^{-7}$ \\
\hline \multicolumn{8}{|l|}{ Well Over-Aged } \\
\hline 7075-T7351 ${ }^{[34]}$ & A & 22 & 600 & 1920 & $1.7 \times 10^{-10}$ & $\sim 10^{-11}$ & $8.0 \times 10^{-10}$ \\
\hline $7049-\mathrm{T} 7351^{[34]}$ & A & 22 & 139 & 720 & $3.4 \times 10^{-10}$ & & $7.6 \times 10^{-10}$ \\
\hline $7475-\mathrm{T} 7351^{[34]}$ & A & 22 & 415 & 1848 & $8.6 \times 10^{-11}$ & & $4.2 \times 10^{-10}$ \\
\hline
\end{tabular}

Test environment: $\mathrm{A}-0.6 \mathrm{M} \mathrm{NaCl}+0.02 \mathrm{M} \mathrm{Na}_{2} \mathrm{Cr}_{2} \mathrm{O}_{7}+0.07 \mathrm{M} \mathrm{CH}_{3} \mathrm{COONa}, \mathrm{pH}=4$

$\mathrm{B}-0.17 \mathrm{M} \mathrm{NaCl}+0.02 \mathrm{M} \mathrm{Na}_{2} \mathrm{Cr}_{2} \mathrm{O}_{7}+0.07 \mathrm{M} \mathrm{CH} \mathrm{CHONa}_{3} \mathrm{pH}=4$.

$\mathrm{C}-0.6 \mathrm{M} \mathrm{NaCl}+2$ pet $\mathrm{Na}_{2} \mathrm{Cr}_{2} \mathrm{O}_{7}$. 
Table VII. Crack Growth Rates for AA7050 in Various Tempers Whilst Exposed to an Inhibited Saline Solution, 0.05 M NaCl + $0.5 \mathrm{M} \mathrm{Na}_{2} \mathrm{CrO}_{4}, \mathrm{pH}=9.2$ and Subjected to Externally Applied Anodic Polarization ${ }^{[83-87,}$, 89]

\begin{tabular}{|c|c|c|c|c|}
\hline \multirow{2}{*}{$\begin{array}{l}\text { AA } 7050 \\
\text { Temp. }\end{array}$} & \multirow{2}{*}{$\begin{array}{l}\text { Applied Potential } \\
\left(\mathrm{mV}_{\mathrm{SCE}}\right)\end{array}$} & \multicolumn{2}{|c|}{ Crack Growth Rate (m/s) } & \multirow{2}{*}{$\begin{array}{l}\text { Post- Incubation } \\
\text { Crack-Tip pH }\end{array}$} \\
\hline & & Initial & Region 2 & \\
\hline -T651 & $\begin{array}{l}-595 \\
-545 \\
-495 \\
-445\end{array}$ & $\begin{array}{l}4 \times 10^{-10} \\
5.8 \times 10^{-10} \\
1.2 \times 10^{-9} \\
-\end{array}$ & $\begin{array}{l}4 \times 10^{-9} \\
1.2 \times 10^{-8} \\
2 \times 10^{-8} \\
7 \times 10^{-8}\end{array}$ & $\begin{array}{l}3.5 \\
3.5 \\
3.5 \\
2\end{array}$ \\
\hline$-\mathrm{T} 6(\mathrm{Lab})$ & -645 & $1.2 \times 10^{-9}$ & - & 4 \\
\hline $6 \mathrm{~h} 436 \mathrm{~K}\left(163^{\circ} \mathrm{C}\right)$ & $\begin{array}{l}-545 \\
-495 \\
-445\end{array}$ & $\begin{array}{l}6 \times 10^{-10} \\
1.2 \times 10^{-9} \text { to } 2 \times 10^{-8}\end{array}$ & $\begin{array}{l}1.2 \times 10^{-8} \\
2 \times 10^{-8} \text { to } 5.4 \times 10^{-8} \\
1.2 \times 10^{-7}\end{array}$ & $\begin{array}{l}3.5 \\
2.5 \text { to } 3 \\
2.5\end{array}$ \\
\hline$-\mathrm{T} 74(\mathrm{Lab})$ & -675 & $5 \times 10^{-9}$ & - & $\sim 8.5$ \\
\hline $12 \mathrm{~h} 436 \mathrm{~K}\left(163^{\circ} \mathrm{C}\right)$ & $\begin{array}{l}-495 \\
-445\end{array}$ & $\begin{array}{l}5.4 \times 10^{-10} \\
5.6 \times 10^{-10}\end{array}$ & $\overline{10}^{-7}$ & $\overline{2.5}$ to 2.7 \\
\hline -T7451 (+ S-Phase) & -445 & $-2 \times 10^{-11}$ & $1.8 \times 10^{-9}$ & 3 \\
\hline AA7075 & $\begin{array}{l}<-293 \\
-710\end{array}$ & $-2 \times 10$ & $\overline{5.5} \times 10^{-8}$ & $\begin{array}{l}\sim 0.5 \\
1.8\end{array}$ \\
\hline $\begin{array}{l}-\mathrm{T} 651 \\
\text { Aq. } 1 \mathrm{M} \mathrm{NaCl}\end{array}$ & $-848(\mathrm{FCP})$ & - & $2 \times 10^{-8}$ & 3.4 \\
\hline
\end{tabular}

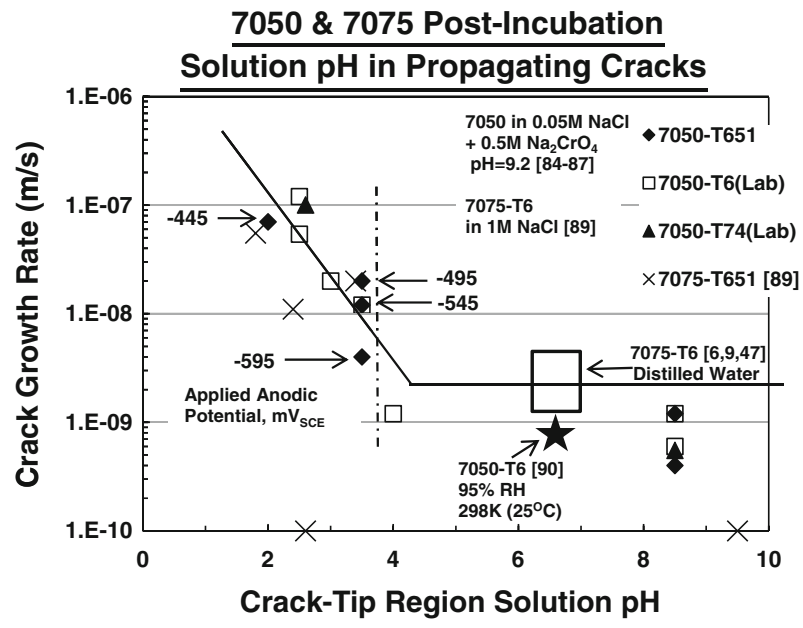

Fig. 21-Region 2 SCC growth rates for high-copper-containing Al$\mathrm{Zn}-\mathrm{Mg}-\mathrm{Cu}$ alloys as a function of the local solution $\mathrm{pH}$ in the propagating crack-tip region.

highly dependent on alloy temper and whether bulk environments contain chromate or dichromate ions, Table VI, and the application of an externally applied anodic potential, Table VII, the local environmental conditions developed within cracks (solution $\mathrm{pH}$ and concentrations of soluble aluminum and chloride ion species) before the transition to faster crack growth rates occurs are remarkably consistent, Table IX.

While it is clear that faster crack growth rates are associated with the development of local acidic environments, enriched in aluminum and chloride species, a delay period after the attainment of these conditions is always required, which for over-aged tempers may be in excess of $1000 \mathrm{~h}$ (Figures 2, 22), and it should be noted similar local solutions are also developed for stress corrosion resistant aluminum alloys where ${ }^{[64,74,89]} \mathrm{crack}$ growth is not promoted. This is not well understood.
Table VIII. Effect of Starter Crack Morphology on SCC Initiation Times for Over-Aged High Strength Al-Zn-Mg-Cu Alloy DCB Tests in 0.6 M NaCl Solution Containing $0.02 \mathrm{M}$ $\mathrm{Na}_{2} \mathrm{Cr}_{2} \mathrm{O}_{7}+0.07 \mathrm{M} \mathrm{CH} \mathrm{CHONa}_{3}$ Acidified to $\mathrm{pH}=4 \mathrm{Using}$

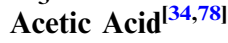

\begin{tabular}{|c|c|c|c|c|}
\hline \multirow[b]{2}{*}{ Alloy } & \multirow{2}{*}{$\begin{array}{l}\text { Yield Stress } \\
\left(\mathrm{MNm}^{-2}\right)\end{array}$} & \multirow{2}{*}{$\begin{array}{l}\text { Initial } K_{1 \mathrm{a}} \\
\left(\mathrm{MNm}^{-3 / 2}\right)\end{array}$} & \multicolumn{2}{|c|}{$\begin{array}{l}\text { SCC Initiation } \\
\text { Time (h) }\end{array}$} \\
\hline & & & Fatigue & "Pop-in" \\
\hline 7075-T7351 & 429 & 21.9 & 600 & 240 \\
\hline 7475-Т7351 & 420 & 24.0 & $>600$ & 240 \\
\hline 7049-T7351 & 461 & 25.0 & 240 & $48 *$ \\
\hline 7050-T73651 & 477 & 24.6 & 120 & $48^{*}$ \\
\hline
\end{tabular}

The experimentally observed minimum chloride ion concentration, $\sim 0.01 \mathrm{M}$, for the local saline environments within restricted geometries to develop solution pHs less than $\sim 4$ is almost certainly associated with the minimum chloride ion concentration needed to appropriately disrupt/modify the local hydrated surfaces formed in the crack-tip region to allow the local generation of oxy-chloro species and a sufficient concentration of $\mathrm{Al}^{3+}$ species to support the equilibrium reaction given earlier in Eq. [1]:

$$
\mathrm{Al}^{3+}+\mathrm{H}_{2} \mathrm{O} \leftrightarrow \mathrm{AlOH}^{2+}+\mathrm{H}^{+}
$$

It is unfortunate the unavailability of appropriate chemical thermodynamic data for the oxy-chloro species $\mathrm{Al}(\mathrm{OH}) \mathrm{Cl}_{2}, \mathrm{Al}(\mathrm{OH})_{2} \mathrm{Cl}$ and $\mathrm{Al}(\mathrm{OH})_{2} \mathrm{Cl}_{2}{ }^{-}$prevents the use of chemical equilibrium calculations to provide further clarification.

SCC susceptibility is governed by an intrinsic property of the alloy temper. Cooper and Kelly ${ }^{[86,87]}$ demonstrated this by micro-injection of a modified local environment into the crack-tip region of a propagating SCC for 
AA7050 in peak- and over-aged tempers. Injection of a simulated "acidified" local environment, dramatically reduced the incubation times required for accelerated crack growth rates in peak-aged material, but had a negligible effect for over-aged (-T7451) material.

\section{B. Mechanistic Implications}

Experimental observations during SCC in $\mathrm{Al}-\mathrm{Zn}-\mathrm{Mg}$ $\mathrm{Cu}$ alloys exposed to saline environments suggest that crack propagation occurs as an intermittent process:

(a) Crack arrest markings have been found on intergranular SCC fracture faces for high purity copper-free Al-5.5Zn-2.5Mg, ${ }^{[2,92]}$ low- and high-copper-containing $\mathrm{Al}-\mathrm{Zn}-\mathrm{Mg}-\mathrm{Cu}$ alloys in acidified-inhibited saline

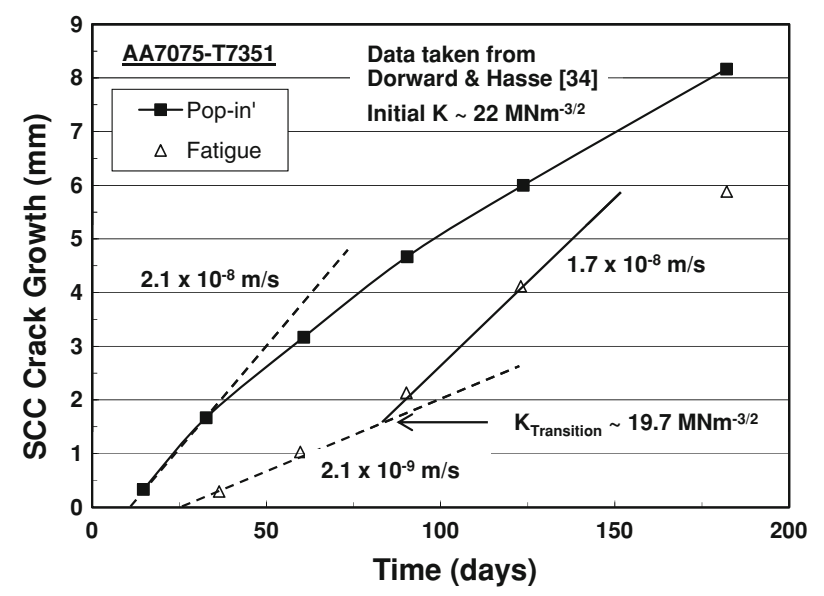

Fig. 22-Effect of starter crack morphology on SCC initiation and growth for AA7075-T7351 in an acidified inhibited solution containing $0.6 \mathrm{M} \mathrm{NaCl} .^{[34]}$ solutions (AA7018-T651, ${ }^{[93]}$ AA7075-T7351 ${ }^{[34]}$ ) and $0.6 \mathrm{M} \mathrm{NaCl}$ (AA7075-T651 ${ }^{[94]}$ ), that closely resemble those seen on intergranular SCCs generated in moist air or distilled water. ${ }^{[95]}$

(b) Time-lapse video studies of crack initiation and growth from notched AA7150-T6 samples immersed in $0.6 \mathrm{M} \mathrm{NaCl},{ }^{[96]}$ have shown that initial crack growth $\left(K=5\right.$ to $\left.18 \mathrm{MNm}^{-3 / 2}\right)$ occurs as a series of discreet steps with crack growth rates greater than $10^{-6} \mathrm{~m} / \mathrm{s}$;

(c) Crack propagation for AA7075-T651 in $0.6 \mathrm{M}$ $\mathrm{NaCl}$ generated a greater number of electrochemical potential fluctuations (electrochemical noise) with a significant increase in the number of events at low frequencies, ${ }^{[97]}$ which are consistent with the anticipated 10 through 20 second intervals between crack growth increments, based on the spacing between crack arrest marking spacing (200 through $400 \mathrm{~nm}^{[93,95]}$ ) and the region $2 \mathrm{SCC}$ growth rate $\left(2 \times 10^{-8} \mathrm{~m} / \mathrm{s}\right.$, Figure 1); and

(d) Output from mini-load cells placed in bolts used during DCB SCC tests on AA7075-T651 totally immersed in $0.6 \mathrm{M} \mathrm{NaCl}$ showed perturbations in crack length-time measurements. ${ }^{[66,98]}$

The experimental fractrographic evidence for discontinuous SCC growth it is less extensive than that for cracking in moist air or distilled water ${ }^{[95]}$ where crack arrest markings are retained on fracture surfaces. However, reported crack arrest mark spacing and crack growth rates for SCC of high and low-copper-containing $\mathrm{Al}-\mathrm{Zn}-\mathrm{Mg}-\mathrm{Cu}$ alloy in saline environments increase by a factor of 3 to 5 compared to those in distilled water or moist air as shown in Table X. Clearly the crack arrest mark spacings during the initial stages of a DCB stress corrosion test in a saline environment, before the crack growth rate increase, should be similar to those in

Table IX. Summary of Solution Chemistry Developed Within Al-Zn-Mg-Cu Alloy Crack-Tip Regions for SCCs Propagating Under Region 2 Loading $\left(K>14 \mathrm{MNm}^{-3 / 2}\right)$

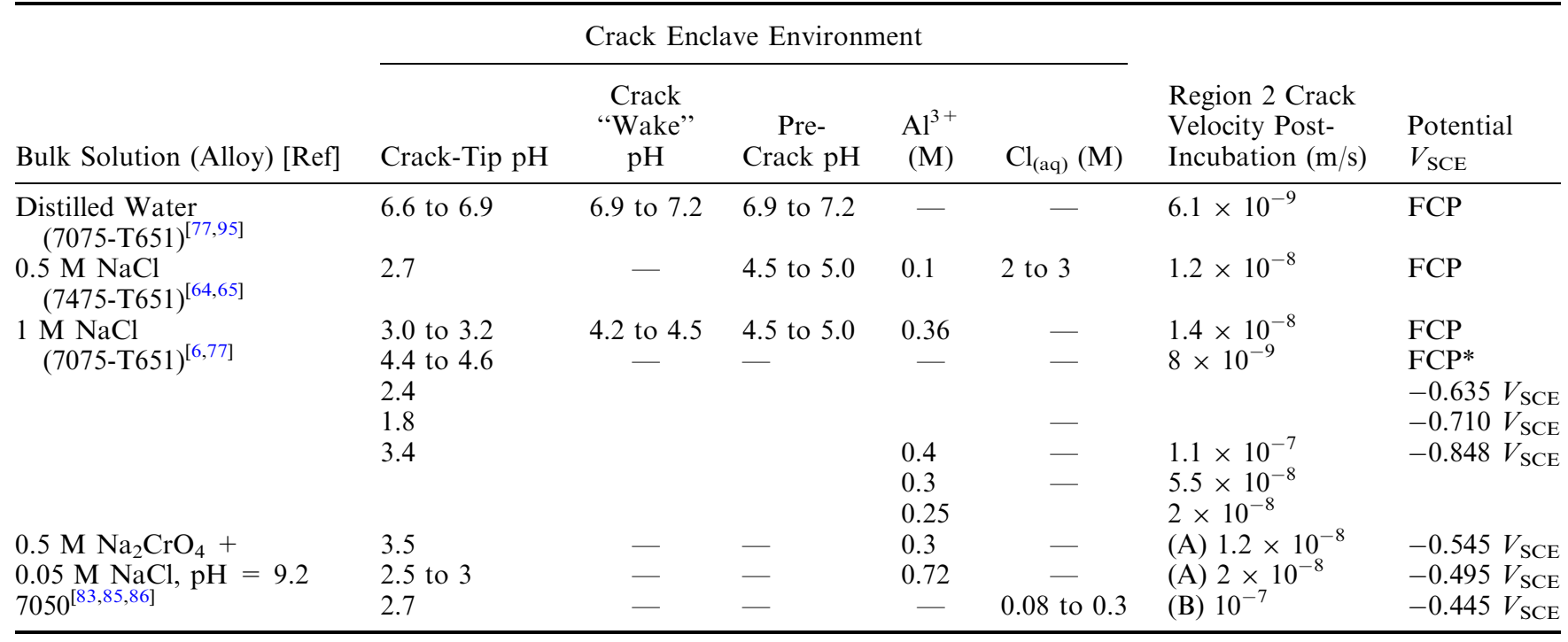

(A) 7050-T651; (B) 7050-T74 (Lab).

* Region 1 loading. 


\begin{tabular}{|c|c|c|c|c|c|c|}
\hline \multirow[b]{2}{*}{ Alloy } & \multirow[b]{2}{*}{$\begin{array}{l}\text { Crack Arrest } \\
\text { Spacing }(\mathrm{nm})\end{array}$} & \multirow[b]{2}{*}{$\begin{array}{l}\text { Crack Growth } \\
\text { Rate }(\mathrm{m} / \mathrm{s})\end{array}$} & \multirow[b]{2}{*}{ Environment } & \multirow[b]{2}{*}{$K\left(\mathrm{MNm}^{-3 / 2}\right)$} & \multicolumn{2}{|c|}{$\begin{array}{l}\text { Relative Increase } \\
\quad \text { (Saline/DW) }\end{array}$} \\
\hline & & & & & $\begin{array}{c}\text { CAM } \\
\text { Spacing }\end{array}$ & $\begin{array}{l}\text { Crack } \\
\text { Growth } \\
\text { Rate }\end{array}$ \\
\hline 7018-T651 & $520^{[93]}$ & $3 \times 10^{-8[33]}$ & $\begin{array}{l}2 \text { pct } \mathrm{NaCl}+0.5 \text { pct } \\
\mathrm{Na}_{2} \mathrm{Cr}_{2} \mathrm{O}_{7}, \mathrm{pH}=3\end{array}$ & $<14$ & 2.9 & 3 \\
\hline 7018-T651 & $180 *[95]$ & $10^{-8[108]}$ & distilled water & 15 & & \\
\hline $7075-\mathrm{T} 651$ & - & $1.2 \times 10^{-8[5]}$ & $0.6 \mathrm{M} \mathrm{NaCl}$ & 20 & - & 4 \\
\hline $7075-\mathrm{T} 651$ & 76 to $172^{[10]}$ & $3 \times 10^{-9[10]}$ & 75 pet $\mathrm{RH}$ & 20 & & \\
\hline $7075-\mathrm{T} 651$ & 200 to $400^{[94]}$ & $1.5 \times 10^{-9[5]}$ & $0.6 \mathrm{M} \mathrm{NaCl}$ & 10 & 3 to 3.5 & 5 \\
\hline $7075-\mathrm{T} 651$ & 57 to $135^{[10]}$ & $4 \times 10^{-10[10]}$ & 75 pct $\mathrm{RH}$ & 13 & & \\
\hline 7075-T7351 & 350 to $500^{[34]}$ & $8 \times 10^{-10[34]}$ & $\begin{array}{l}0.6 \mathrm{M} \mathrm{NaCl}+0.02 \mathrm{M} \\
\mathrm{Na}_{2} \mathrm{Cr}_{2} \mathrm{O}_{7} \\
+0.07 \mathrm{M} \mathrm{CH}{ }_{3} \mathrm{COONa} \\
\mathrm{pH}=4\end{array}$ & $>14$ & - & $>5$ \\
\hline 7075-T7351 & - & $\sim 10^{-11[47]}$ & 100 pct $\mathrm{RH}$ & $>14$ & & \\
\hline
\end{tabular}

Table XI. Crack Propagation Activation Energies (kJ/mol) for Low- and High Copper Alloys

\begin{tabular}{|c|c|c|c|c|c|}
\hline \multirow[b]{2}{*}{ Load } & \multicolumn{2}{|c|}{ Low Copper } & \multirow[b]{2}{*}{ Temperature $\left[\mathrm{K}\left({ }^{\circ} \mathrm{C}\right)\right]$} & \multicolumn{2}{|c|}{ High Copper } \\
\hline & Distilled Water & $0.6 \mathrm{M} \mathrm{NaCl}$ & & Distilled Water & $0.6 \mathrm{M} \mathrm{NaCl}$ \\
\hline \multirow[t]{2}{*}{ Region 1} & $\sim 100$ & 85 & $<313(40)$ & 90 & $40 * *$ \\
\hline & 35 to 40 & 80 to $85^{*}$ & $>313(40)$ & 40 to 50 & 20 to 40 \\
\hline \multirow[t]{2}{*}{ Region 2} & 40 to 45 & 80 to 85 & $<313(40)$ & 80 & $40 * *$ \\
\hline & 35 to 40 & $80^{*}$ & $>313(40)$ & 35 to 40 & 20 to 40 \\
\hline
\end{tabular}

*Note that the activation energy was reduced to 15 to $20 \mathrm{~kJ} / \mathrm{mol}$ when crack propagation was stimulated by anodic polarization. ${ }^{[9,47]}$

** de Jong ${ }^{[7]}$ data suggests $E_{\mathrm{a}}$ is 80 to $85 \mathrm{~kJ} / \mathrm{mol}$ under region 1 loading.

water or moist air, whereas, those after should be larger. Consistent observations of these crack arrest markings will be hampered by the subsequent reactivity of the crack-wake surfaces in the local environment within the crack, leading to local solution $\mathrm{pH}$ increases, Table IX.

The activation energies, $E_{\mathrm{a}}$, for SCC growth in Al-Zn$\mathrm{Mg}-\mathrm{Cu}$ alloys fall into the same two categories, as previously reported for SCC in moist air and distilled water, ${ }^{[95]}$ with $E_{\mathrm{a}} \mathrm{s}$ of 20 through 40 and 80 through $100 \mathrm{~kJ} / \mathrm{mol}$. A summary of the activation energy, $E_{\mathrm{a}}$, data for SCC under region $1\left(K=10\right.$ to $\left.12 \mathrm{MNm}^{-3 / 2}\right)$ and region $2\left(K>14 \mathrm{MNm}^{-3 / 2}\right)$ loading conditions at temperatures greater than and less than $313 \mathrm{~K}\left(40{ }^{\circ} \mathrm{C}\right)$ for low- and high-copper alloys immersed in a $0.6 \mathrm{M}$ sodium chloride solution and in distilled water, ${ }^{[95]}$ respectively, is shown in Table XI.

The activation energy values $\left(E_{\mathrm{a}}\right)$ for crack propagation in alloys containing various levels of copper content exposed to a $0.6 \mathrm{M} \mathrm{NaCl}$ solution and distilled water may be summarized as follows.

For low-copper-containing alloys, $E_{\mathrm{a}}$ is 80 through $85 \mathrm{~kJ} / \mathrm{mol}$, irrespective of temperature or loading condition, whereas in distilled water, $E_{\mathrm{a}}$ is consistently around $40 \mathrm{~kJ} / \mathrm{mol}$ (other than for region 1 loading at temperatures less than $313 \mathrm{~K}\left(40^{\circ} \mathrm{C}\right)$, where $E_{\mathrm{a}}$ is $\sim 100 \mathrm{~kJ} / \mathrm{mol}$ ).

For high-copper-containing alloys, irrespective of temperature or loading condition, $E_{\mathrm{a}}$ for SCC in $0.6 \mathrm{M}$ sodium chloride is usually 20 through $40 \mathrm{~kJ} / \mathrm{mol}$ (de Jong's ${ }^{[7]}$ findings for region 1 loading being an exception where for temperatures less than $313 \mathrm{~K}$ $\left(40{ }^{\circ} \mathrm{C}\right) E_{\mathrm{a}}$ was 80 through $\left.85 \mathrm{~kJ} / \mathrm{mol}\right)$ and in distilled water, the $E_{\mathrm{a}}$ is consistently around $40 \mathrm{~kJ} / \mathrm{mol}$, other than for region 1 loading, where $E_{\mathrm{a}}$ was around $90 \mathrm{~kJ} / \mathrm{mol}$.

This means that the presence of chloride ions causes the $E_{\text {a }}$ for crack propagation in low-copper-containing alloys to increase from $\sim 40 \mathrm{~kJ} / \mathrm{mol}$ (in distilled water) to $\sim 85 \mathrm{~kJ} / \mathrm{mol}$ for temperatures greater than and less than $313 \mathrm{~K}\left(40^{\circ} \mathrm{C}\right)$, whereas, for high-copper-containing Al$\mathrm{Zn}-\mathrm{Mg}-\mathrm{Cu}$ alloys the reverse change $(\sim 85$ to $\sim 40 \mathrm{~kJ} /$ mol) was usually observed for temperatures less than $313 \mathrm{~K}\left(40{ }^{\circ} \mathrm{C}\right)$, and no change was promoted for temperature greater than $313 \mathrm{~K}\left(40^{\circ} \mathrm{C}\right)$, i.e., $E_{\mathrm{a}}$ remained at $\sim 20$ through $40 \mathrm{~kJ} / \mathrm{mol}$.

Attaching mechanistic significance to apparent activation energies is controversial. ${ }^{[39,82,95]}$ Candidate processes with activation energies in the ranges of 20 
Table XII. Activation Energies for Candidate Rate-Controlling Processes

\begin{tabular}{|c|c|c|c|}
\hline Process & $E_{\mathrm{a}}(\mathrm{kJ} / \mathrm{mol})$ & Temperature Range $\left[\mathrm{K}\left({ }^{\circ} \mathrm{C}\right)\right]$ & Ref. \\
\hline \multicolumn{4}{|l|}{ Anodic Dissolution } \\
\hline Aluminum Alloys in Aqueous Solutions & 80 to 100 & $\sim 298(25)$ & 109 \\
\hline $\begin{array}{l}\text { Pure Aluminum in De-Aerated } \\
3.5 \text { pct } \mathrm{NaCl}, \mathrm{pH}=6\end{array}$ & 89 & 298 to $328(25$ to 55$)$ & 110 \\
\hline Pure Aluminum in $1 \mathrm{M} \mathrm{HClO}_{4}$ & {$\left[79^{*}\right]\left(13^{*}\right)$} & [ ] 293 to $313(20$ to 40$)$ & 111 \\
\hline 3 pct $\mathrm{NaCl}, \mathrm{pH}=1.3$ & {$[27 *](27 *)$} & ( ) 313 to 338 (40 to 65$)$ & 111 \\
\hline AA7075-T651 in 3 pet $\mathrm{NaCl}, \mathrm{pH} \sim 6-7$ & {$[27 *](27 *)$} & Re-calculated* & 112 \\
\hline \multicolumn{4}{|l|}{ Deformation } \\
\hline Aluminum Creep & 116 & 273 to $373(0$ to 100$)$ & 113 \\
\hline Grain Boundary Sliding in Al-Zn-Mg & 110 & 293 to $373(20$ to 100$)$ & 102 \\
\hline \multirow[t]{2}{*}{ Film Formation on Aluminum in Distilled Water } & 100 & 293 to $318(20$ to 45$)$ & 75 \\
\hline & 79 & 318 to 368 (45 to 90$)$ & 75 \\
\hline Water Exchange in Hydrated $\mathrm{Al}(\mathrm{III})$ Complexes & $\sim 36$ & $295(22)$ & 99,100 \\
\hline Al to $\mathrm{AlH}_{3}$ Within Nano-Spaces, e.g., Cracks & $\sim 34$ & 298 to 348 ( 25 to 75$)$ & 101 \\
\hline $\mathrm{AlH}_{3}$ Hydration to $\mathrm{Al}_{2} \mathrm{O}_{3}+\mathrm{H}_{2}$ & $\sim 34$ & 313 to $383(40$ to 80$)$ & 101 \\
\hline $\begin{array}{l}\text { Pit Induction Time for Pre-Anodized } \\
\text { Pure } \mathrm{Al} \text { in } 0.1 \mathrm{M} \mathrm{KCl}\end{array}$ & $\sim 20$ & 278 to $328(5$ to 55$)$ & 72 \\
\hline \multicolumn{4}{|l|}{ Hydrogen Diffusion } \\
\hline Pure Aluminum & 55 & 285 to $328(12$ to 55$)$ & 114 \\
\hline Lattice & 16.2 & 303 to 893 (30 to 600$)$ & 115 \\
\hline AA7050-UA & 15.8 & & 116 \\
\hline AA7050-PA & 16.1 & $\begin{array}{l}\text { extrapolated from data at } \\
423 \text { to } 523(150 \text { to } 250)\end{array}$ & 116 \\
\hline AA7050-OA & 32.7 & & 116 \\
\hline AA7050-low Cu-PA & 14.2 & & 116 \\
\hline AA7050-low Cu-OA & 14.2 & & 116 \\
\hline
\end{tabular}

through 40 and 80 through $100 \mathrm{~kJ} / \mathrm{mol}$, are shown in Table XII.

Although both anodic dissolution (AD) and grain boundary sliding (GBS) with apparent activation energies of 80 through $100 \mathrm{~kJ} / \mathrm{mol}$ and a hydrogen diffusion based process with apparent activation energies around $20 \mathrm{~kJ} / \mathrm{mol}$ are candidate processes, it is difficult to identify processes with apparent activities ranging from 35 to $40 \mathrm{~kJ} / \mathrm{mol}$, other than a water exchange reaction for a hydrated $\mathrm{Al}(\mathrm{III})$ complex, $\mathrm{Al}\left(\mathrm{H}_{2} \mathrm{O}\right)_{6}^{3+}(\mathrm{aq})$, involving a de-protonation of a single water molecule to generate the complex $\mathrm{AlOH}\left(\mathrm{H}_{2} \mathrm{O}\right)_{5}^{2+}{ }^{[99,100]}$ and recently published values for the generation and decomposition of aluminum hydride, $\mathrm{AlH}_{3}$. ${ }^{[101]}$

It is possible that although crack propagation in $\mathrm{Al}-\mathrm{Zn}-\mathrm{Mg}-\mathrm{Cu}$ alloys occurs by a hydrogen related process, the rate-controlling process under specific circumstances is determined by local environmental and alloy microstructural conditions, which are influenced by the alloy chemistry, and/or the prevailing loading conditions and temperature. For instance, the supply of hydrogen may be dictated by an electrochemical reaction and/or the availability of local reactive surfaces generated by GBS and be rate limiting $\left(E_{\mathrm{a}}, 80\right.$ through $100 \mathrm{~kJ} /$ mol) or a process within the alloy microstructure to utilize locally available hydrogen could be the ratecontrolling process $\left(E_{\mathrm{a}} \sim 40 \mathrm{~kJ} / \mathrm{mol}\right)$, as recently proposed for crack growth in distilled water. ${ }^{[95]}$

Lee et al. ${ }^{[22]}$ proposed that intergranular SCC initiation and propagation for $\mathrm{Al}-\mathrm{Zn}-\mathrm{Mg}-\mathrm{Cu}$ alloys in aqueous solutions under region 1 loading is primarily under AD control with a gradual transition to hydrogen embrittlement (HE) control as the loading conditions intensify, such that crack growth is under HE control when region 2 loading conditions are established. Their proposal was based on an experimental observation that the threshold stress intensity factor, $K_{1 \mathrm{SCC}}$ for crack initiation for AA7039 exposed to $0.6 \mathrm{M} \mathrm{NaCl}$ over the temperature range $298 \mathrm{~K}$ to $328 \mathrm{~K}\left(25^{\circ} \mathrm{C}\right.$ through $55^{\circ} \mathrm{C}$ ) decreased with increasing temperature, in agreement with their model's prediction, whereas had HE been be the rate-controlling process the reverse temperature dependency would have been observed.

Further support for the idea that crack initiation and initial growth is under $\mathrm{AD}$ control at temperatures less than around $313 \mathrm{~K}\left(40^{\circ} \mathrm{C}\right)$ is provided by Magnin et $a l^{[102]}$ who considered that anodic dissolution must provide a critical surface defect during the initiation of $\mathrm{SCC}$ in smooth specimens for an Al-Zn-Mg-Cu alloy containing $\sim 2$ pct $\mathrm{Cu}, \mathrm{AA} 7150$, before hydrogen relatedeffects can occur. The proposals by Magnin et al ${ }^{[102]}$ and Lee et al. ${ }^{[2]}$ that crack initiation in saline solutions is associated with AD are consistent with the reported apparent activation energy, $E_{\mathrm{a}} \sim 110 \mathrm{~kJ} / \mathrm{mol},{ }^{[39,103]}$ for intergranular crack initiation in copper-free Al-Zn-Mg alloys over the temperature range of $293 \mathrm{~K}$ through $353 \mathrm{~K}$ $\left(20{ }^{\circ} \mathrm{C}\right.$ through $80{ }^{\circ} \mathrm{C}$ ) and 80 to $100 \mathrm{~kJ} / \mathrm{mol}^{[22,23]}$ for crack growth under region 1 and 2 loading conditions for lowcopper-containing $\mathrm{Al}-\mathrm{Zn}-\mathrm{Mg}-\mathrm{Cu}$ alloys in saline solutions, Table XI. For high-copper-containing alloys, while crack initiation, probably remains under anodic dissolution control, an early change to a controlling hydrogen related process is consistent with the observed activation energies for cracking in saline environments, Table XI. 
The influence of local environmental conditions on crack initiation from smooth surfaces can also provide some insight into rate controlling mechanisms. Experimental results by Abe et al. ${ }^{[103]}$ demonstrated that the critical stress for intergranular crack initiation in a peakaged $\mathrm{Al}-6 \mathrm{Zn}-1.6 \mathrm{Mg}$ alloy at temperatures from room temperature up to $323 \mathrm{~K}\left(50{ }^{\circ} \mathrm{C}\right)$ was insensitive to the environmental test conditions (lab air, distilled water, 3 pct $\mathrm{NaCl}$ or glycerin). Cracking initiating almost immediately on loading to stresses greater than the 0.2 pct proof stress, while for lower stress, greater than a critical minimum, an incubation time was required for sharp intergranular cracks to initiate by a thermally activated process with an activation energy of $109 \mathrm{~kJ} / \mathrm{mol}$. Pathania and Tromans ${ }^{[39]}$ reported the same activation energy for crack initiation from the base of smooth machined notched tensile bars for a high purity $\mathrm{Al}-6.3 \mathrm{Zn}-2.6 \mathrm{Mg}$ alloy in a slightly over-aged temper exposed to an acidified-inhibited aqueous $0.6 \mathrm{M} \mathrm{NaCl}$ solution, $\mathrm{pH}=4$.

Abe et $a l^{[103]}$ also demonstrated that cathodic precharging with hydrogen reduced the $E_{\mathrm{a}}$ for crack initiation from 109 to $47 \mathrm{~kJ} / \mathrm{mol}$, at temperatures less than $\sim 313 \mathrm{~K}\left(40{ }^{\circ} \mathrm{C}\right)$ but not at higher temperatures, adding support to different rate controlling steps being operative greater than and less than $\sim 313 \mathrm{~K}\left(40^{\circ} \mathrm{C}\right)$.

Our findings for low-copper-containing alloys in saline solutions, where we suggest GBS in tandem with an surface-sensitive electrochemical reaction with the local environment is rate controlling, concur with Starke and coworkers ${ }^{[37,104-106]}$ proposal that the rate controlling processes during SCC for peak- and over-aged $\mathrm{Al}-6 \mathrm{Zn}-2 \mathrm{Mg}-\mathrm{X}$ pet $\mathrm{Cu}$ alloys in a 3 pet $\mathrm{NaCl}$ solution at room temperature is the slip-deformation mode for alloys containing less than around 1 pct $\mathrm{Cu}$, for which over-aging only provides a minor improvement in crack growth resistance.

Our findings for higher-copper-containing alloys in saline solutions differ from Starke and coworkers ${ }^{[37,104-106]}$ proposal in that the slip-deformation mode was rate controlling under region 1 loading conditions $\left(K<\sim 14 \mathrm{MNm}^{-3 / 2}\right)$, and electrochemical control was rate controlling for region 2 loading conditions $\left(K>\sim 14 \mathrm{MNm}^{-3 / 2}\right)$. The apparent activation energies of 20 through $40 \mathrm{~kJ} / \mathrm{mol}$ observed for high coppercontaining alloys under region 1 and 2 loading conditions at temperatures greater than and less than $313 \mathrm{~K}\left(40{ }^{\circ} \mathrm{C}\right)$ is indicative that something other than slip-deformation mode has become rate controlling, which could involve hydrogen within the alloy undergoing a time-dependent strain-induced process such as aluminum hydride, $\mathrm{AlH}_{3}$, generation, as proposed by Ciaraldi et al. ${ }^{[107]}$

Rationalization of the above may be that, as noted earlier, the heat treatments used by Starke and coworkers on their Al-6Zn-3Mg-XCu alloys would have generated over-aged tempers, with apparent activation energies of $\sim 85 \mathrm{~kJ} / \mathrm{mol}$, which would be consistent with an electrochemical process becoming rate controlling.

\section{Influence of Alloy Composition}

Consideration of the region 2 SCC growth data provided in Table III as a function of alloy composition reveals the critical alloys compositional factors controlling the SCC susceptibility of $\mathrm{Al}-\mathrm{Zn}-\mathrm{Mg}-\mathrm{Cu}$ alloys are the copper content, $\mathrm{Zn} / \mathrm{Mg}$ ratio, and the excess magnesium concentration, Table XIII.

Evaluation of the data shown in Table XIII indicates that over-aging $\mathrm{Al}-\mathrm{Zn}-\mathrm{Mg}-\mathrm{Cu}$ alloys containing

(a) less than $\sim 0.8 \mathrm{wt}$ pct copper does not significantly reduce the observed region 2 SCC growth rates, however, it should be noted all the alloys evaluated here in this category also had excess magnesium levels well greater than $1 \mathrm{wt}$ pet and $\mathrm{Zn} / \mathrm{Mg}$ ratios well less than 2,

(b) copper contents greater than $\sim 0.8 \mathrm{wt}$ can significantly reduce region $2 \mathrm{SCC}$ growth rates, however, it is clear with industries move to using richer alloys (i.e., 7075 through 7050, $7010 \& 7150$, and more recently to 7055 and 7085 ), these beneficial effects become less marked for a given level of overaging, despite the newer alloys having reduced excess magnesium levels and in the case of $7055 \mathrm{a}$ more optimized $\mathrm{Zn} / \mathrm{Mg}$ ratio.

Based on the data given in Tables III and XIII, it is reasonable to conclude that the SCC resistance of peakand over-aged $\mathrm{Al}-\mathrm{Zn}-\mathrm{Mg}-\mathrm{Cu}$ alloys containing less than $\sim 8 \mathrm{wt}$ pct zinc will be optimized with excess magnesium less than around $1 \mathrm{wt}$ pct, $\mathrm{Zn} / \mathrm{Mg}$ ratios ranging from 2 to 3 and copper levels less than $0.2 \mathrm{wt}$ pct or ranging from 1.3 to 2 .

Table XIII. Chemical Composition Factors Controlling the SCC of Al-Zn-Mg-Cu Alloys, Summarized Data from Table III

\begin{tabular}{|c|c|c|c|c|c|c|c|}
\hline & \multirow[b]{2}{*}{$\mathrm{Cu}-$ Free } & \multirow{2}{*}{$\begin{array}{c}\text { Low-Cu } \\
7017,7039\end{array}$} & \multirow{2}{*}{$\begin{array}{c}\text { Med-Cu } \\
7079,7022 *\end{array}$} & \multirow{2}{*}{$\begin{array}{c}\text { Med-Cu } \\
7022^{* *}\end{array}$} & \multicolumn{3}{|c|}{ High-Cu } \\
\hline & & & & & 7075 & 7050 & 7055 \\
\hline $\mathrm{Cu}(\mathrm{Wt}$ pct $)$ & 0 & 0.1 to 0.13 & 0.5 to 0.8 & 0.8 to 0.95 & 1.26 to 1.59 & 2.1 & 2.04 \\
\hline $\mathrm{Zn} / \mathrm{Mg}$ Ratio & 2.2 to 2.4 & 1.4 to 1.83 & 1.1 to 1.36 & 1.53 to 1.59 & 1.44 to 2.82 & 2.63 & 3.24 \\
\hline Excess $\mathrm{Mg}(\mathrm{Wt} \mathrm{pct})$ & 1.3 to 1.5 & 1.5 to 2 & 2.1 to 2.4 & 1.74 to 1.91 & 0.55 to 1 & 0.06 to 0.36 & 0.06 \\
\hline \multicolumn{8}{|l|}{ Crack Velocity $(\mathrm{m} / \mathrm{s})$} \\
\hline T6 & $\begin{array}{l}4.8 \times 10^{-8} \\
6 \times 10^{-8}\end{array}$ & $\begin{array}{l}2 \times 10^{-8} \\
3.5 \times 10^{-8}\end{array}$ & $\begin{array}{l}10^{-7} \\
2.5 \times 10^{-6}\end{array}$ & $\begin{array}{l}8.1 \times 10^{-9} \\
1.7 \times 10^{-8}\end{array}$ & $\begin{array}{l}6 \times 10^{-9} \\
1.2 \times 10^{-8}\end{array}$ & $3 \times 10^{-8}$ & $4 \times 10^{-8}$ \\
\hline T76 & $1.2 \times 10^{-8}$ & $\begin{array}{l}8.8 \times 10^{-9} \\
2 \times 10^{-8}\end{array}$ & $\begin{array}{l}10^{-7} \\
2.5 \times 10^{-6}\end{array}$ & $2 \times 10^{-9}$ & $10^{-9}$ & $10^{-9}$ & $1.2 \times 10^{-9}$ \\
\hline
\end{tabular}




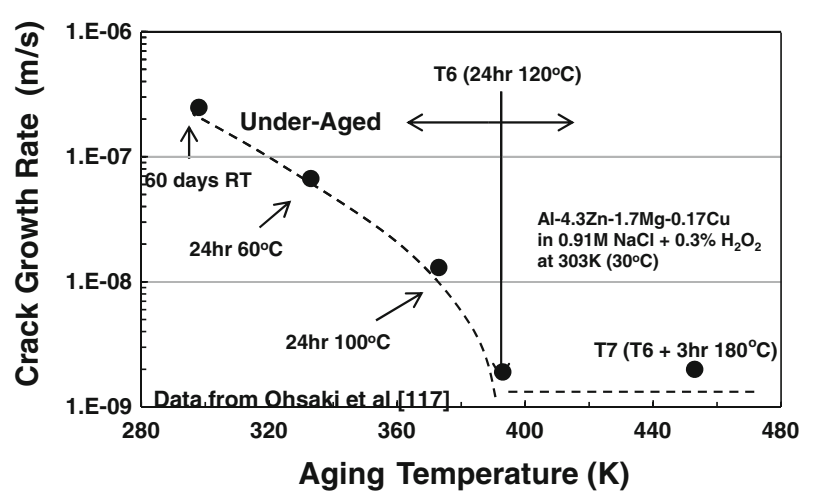

Fig. 23-Crack growth rates at $K=18 \mathrm{MNm}^{-3 / 2}$ for $\mathrm{Al}-\mathrm{Zn}-\mathrm{Mg}-\mathrm{Cu}$ alloy, $7 \mathrm{~N} 01(\mathrm{Al}-4.3 \mathrm{Zn}-1.7 \mathrm{Mg}-0.17 \mathrm{Cu})$ in various tempers exposed to $0.91 \mathrm{M} \mathrm{NaCl}+0.3$ pct $\mathrm{NaCl}, \mathrm{pH}=5$ at $303 \mathrm{~K}\left(30^{\circ} \mathrm{C}\right) \cdot .^{[117]}$

\section{CONCLUDING REMARKS}

Discussion in this article has focused on peak- and over-aged alloy tempers because only limited data are available for under-aged alloy tempers. Data available indicates crack growth rates for under-aged tempers for both low- and high-copper-containing $\mathrm{Al}-\mathrm{Zn}-\mathrm{Mg}-\mathrm{Cu}$ alloys consistently exceed those for peak- and over-aged tempers, often being at least two orders of magnitude greater for highly under-aged tempers, Figure 23, while the apparent activation energies remain similar to those observed for peak-aged tempers, Table IV.

Clearly further study is needed to justify the assertion, but it is probable that crack propagation in $\mathrm{Al}-\mathrm{Zn}-\mathrm{Mg}-\mathrm{Cu}$ alloys exposed to saline environments (and distilled water), irrespective of alloy's copper content, loading condition or ambient temperature up to $353 \mathrm{~K}\left(80{ }^{\circ} \mathrm{C}\right)$, occurs by a hydrogen related process, with the ratecontrolling process under specific circumstances determined by the local (and bulk) environmental conditions, the alloy chemistry and the prevailing loading conditions. The difference between crack growth rates in distilled water and saline solutions being dictated by the relative availability of monatomic hydrogen from local environments developed within crack-tip regions with $\mathrm{pHs}$ of 5.5 to 7 for distilled water and $\sim 3$ in saline solutions.

Future SCC studies on $\mathrm{Al}-\mathrm{Zn}-\mathrm{Mg}-\mathrm{Cu}$ alloys should focus on establishing the critical factors controlling crack initiation. This is because although crack initiation times during service-life in current commercial applications are sufficiently long to minimize "in-service" problems, reliance on long SCC initiation times for the next generation of higher-strength $\mathrm{Al}-\mathrm{Zn}-\mathrm{Mg}-\mathrm{Cu}$ alloys may be imprudent, particularly as they are likely to be loaded to higher stress levels.

\section{SUMMARY OF OBSERVATIONS AND CONCLUSIONS}

1. The critical factors that control stress corrosion susceptibility of peak- and over-aged $\mathrm{Al}-\mathrm{Zn}-\mathrm{Mg}-\mathrm{Cu}$ alloys in saline solutions at ambient temperatures are copper content, $\mathrm{Zn} / \mathrm{Mg}$ ratio and excess magnesium.
2. SCC resistance is optimized for peak- and overaged alloys containing less than $\sim 8$ pet $\mathrm{Zn}$ by alloys with excess magnesium less than $1 \mathrm{wt}$ pct, $\mathrm{Zn} /$ $\mathrm{Mg}$ ratios ranging from 2 to 3 and copper levels either less than $0.2 \mathrm{wt}$ pct or ranging from 1.3 to $2 \mathrm{wt}$ pct.

3. Over-aging is a beneficial treatment for $\mathrm{Al}-\mathrm{Zn}-\mathrm{Mg}$ $\mathrm{Cu}$ alloys with copper content greater than about $0.8 \mathrm{wt}$ pct and zinc contents less than $\sim 8 \mathrm{wt}$ pct, whereas it is ineffective for alloy compositions with lower copper contents.

4. SCC growth rates for peak-aged $\mathrm{Al}-\mathrm{Zn}-\mathrm{Mg}-\mathrm{Cu}$ alloys in saline solutions are similar to those promoted in distilled water when chloride concentrations are less than $\sim 0.01 \mathrm{M}$. Crack growth rates increase with chloride concentration to a maximum rate at around $0.6 \mathrm{M}$. A minimum chloride concentration of $0.01 \mathrm{M}$ is required to insure that local environment conditions developed within restricted geometries maintain a $\mathrm{pH}$ less than 4 .

5. SCC growth rates under region 2 loading conditions $\left(K>14 \mathrm{MNm}^{-3 / 2}\right)$ for AA7075-T651 in acidified-inhibited saline solution based on $0.02 \mathrm{M}$ sodium dichromate and $0.07 \mathrm{M}$ sodium acetate containing at least $0.01 \mathrm{M}$ chloride and acidified to a $\mathrm{pH}$ of 4 using acetic acid are insensitive to chloride ion concentration, and crack growth rates are at least double the maximum rates observed in aqueous sodium chloride solutions without any additions.

6. SCC initiation and growth from fatigue precracked test specimens immersed in saline solutions undergo the following sequence of events:

(a) An initial period with no detectible crack growth

(b) Crack growth at a rate equivalent to that observed in distilled water

(c) Accelerated crack growth

7. Time spent in each stage is sensitive to factors including the type of pre-crack (mechanical "popin" or fatigue), applied stress intensity factor, alloy chemistry and temper, bulk solution additives and external polarization.

8. SCC growth for peak- and over-aged Al-Zn-Mg-Cu alloys in saline environments at ambient temperatures $\left[R T\right.$ to $\left.353 \mathrm{~K}\left(80{ }^{\circ} \mathrm{C}\right)\right]$ probably involves a hydrogen related process, with the RDS for peakaged low-copper-containing alloys under electrochemical/deformation control ( $E_{\mathrm{a}}$ of 80 to $85 \mathrm{~kJ} / \mathrm{mol}$ ), whereas, for high-copper-containing alloys the RDS for peak-aged alloys is no longer under electrochemical control but probably directly controlled by a hydrogen related process within the alloy microstructure ( $E_{\mathrm{a}}$ of 20 to $\left.40 \mathrm{~kJ} / \mathrm{mol}\right)$, and the RDS for over-aged alloys reverts once more under electrochemical control $\left(E_{\mathrm{a}} \sim 85 \mathrm{~kJ} / \mathrm{mol}\right)$.

9. It is conceivable that crack propagation in Al- $\mathrm{Zn}-\mathrm{Mg}$ $\mathrm{Cu}$ alloys exposed to saline environments or distilled water at ambient temperatures up to $353 \mathrm{~K}\left(80^{\circ} \mathrm{C}\right)$, irrespective of alloy's copper content or loading condition occurs by a hydrogen related process, with the 
rate-controlling process under specific circumstances being determined by factors including, the local (and bulk) environmental conditions, the alloy chemistry and the prevailing loading conditions.

10. Differences between crack growth rates in distilled water and saline solutions are most likely due to the relative availability of monatomic hydrogen from the local environments developed within propagating cracks with $\mathrm{pHs}$ of 5.5 to 7 for distilled water and $\sim 3$ for saline solutions.

\section{REFERENCES}

1. J.H. Mulherin: Stress Corrosion Testing, ASTM-STP 425, Philadelphia, PA, 1967, pp. 66-81.

2. A.J. McEvily, J.B. Clark, and A.P. Bond: Trans. ASM, 1967, vol. 60 , pp. $661-71$.

3. R. Shipp: Research Report A1747, The British Non-Ferrous Metal Research Association, London, October 1969.

4. M.V. Hyatt: Reports DC-24466, DC-24467, DC-24469, DC24470, The Boeing Company, Seattle, November 1969.

5. M.V. Hyatt: Corrosion, 1970 , vol. 26, pp. 487-503.

6. A.H. Le and R.T. Foley: Corrosion, 1983, vol. 39, pp. 379-83.

7. H.F. de Jong: Aluminium, 1981, vol. 11, pp. 526-31.

8. L.R. Hall, R.W. Finger, and W.F. Spurr: Report AFML-TR-73204, The Boeing Company, Seattle, September, 1973.

9. M.O. Speidel: in The Theory of Stress Corrosion Cracking in Alloys, J.C. Scully, ed., NATO, Brussels, Belgium, 1971, pp. 298-344.

10. S.P. Knight: Ph.D. Thesis, Monash University, Melbourne, 2008.

11. S.P. Lynch, S.P. Knight, N. Birbillis, and B.C. Muddle: in Effects of Hydrogen in Metals, B. Somerday, P. Sofronis, and R. Jones, eds., ASM International, Materials Park, 2009, pp. 243-50.

12. D.O. Sprowls, M.B. Shoemaker, J.D. Walsh, and J.W. Coursen: Final Report, Prepared for George C. Marshall Space Flight Center, Alabama, Contract No. NAS-8021487-Part 1, May 31, 1973.

13. J.D. Kaufman, J.W Coursen, and D.O. Sprowls: ASTM-610, H.L. Craig, Jr., ed., ASTM, Philadelphia, PA, 1976, pp. 94-107.

14. K.L. Deffenbaugh: United States Naval Academy Trident Scholar Report No. 304, April 2003.

15. M. Cook, R. Chadwick, and N.B. Muir: J. Inst. Met., 1951, vol. 79, pp. 293-320.

16. L.H. Chambers and D.C. Baxter: Engineer, 1967, vol. 223, pp. 518-20.

17. K.G. Kent: Metall. Rev., 1970, vol. 15 (147), pp. 135-46.

18. W. Gruhl: Aluminium, 1978, vol. 54, pp. 323-25.

19. K.R. Anderson: U.S. Patent 5,312,498, May 17, 1994.

20. N.J.H. Holroyd: in Environment-Induced Cracking of Metals, R.P Gangloff and M.B Ives, eds., NACE, Houston, TX, 1990, pp. 311-45.

21. C.M. Liao: Corrosion, 1993, vol. 49, pp. 52-59.

22. S. Lee, S.L. Pyun, and Y. Chun: Metall. Trans. A, 1991, vol. 22A, pp. 2407-14.

23. S. Pyun, M. Hong, and H. Kim: Br. Corros. J., 1991, vol. 26, pp. 260-64.

24. N.J.H. Holroyd and D. Hardie: Corros. Sci., 1983, vol. 23, pp. $527-46$.

25. L.P. Huang, K.H. Chen, S. Li, and M. Song: Scripta Mater., 2007, vol. 56, pp. 305-08.

26. J.E. Finnegan and W.H. Hartt: in Stress Corrosion-New Approaches, ASTM-STP 610, H.L. Craig, ed., ASTM, Philadelphia, PA, 1976, pp. 44-60.

27. J.K. Park: Mater. Sci. Eng., 1988, vol. A103, pp. 223-31.

28. E.C.H. Pow: Master's Thesis, University of Minnesota, 1979

29. E.C.H. Pow: Ph.D. Thesis, University of Minnesota, 1982

30. S. Osaki, D. Itoh, and M. Nakai: J. Jpn. Inst. Light Met., 2001, vol. 51 , pp. 222-27.

31. B. Jegdic and B. Bobic: Zastita Mater., 2007, vol. 48, pp. 14-18.

32. M.O. Speidel, R. Machler, and R. Magdowski: in 3rd International Conference on Aluminum Alloys (ICAA3), L. Arnberg, O. Lohne, E. Ness, and N. Ryum, eds., Trondheim, Norway, 1992, pp. 461-66.
33. N.J.H. Holroyd and D. Hardie: Met. Technol., 1982, vol. 9, pp. 229-34.

34. R.C. Doward and K.R. Hasse: Final NASA Report Contract No. NAS8-30890, Oct. 1976.

35. J. Robinson and P. Flynn: Key Eng. Mater., 1995, vols. 99-100, pp. $143-50$

36. B.J. Connelly, M.G. Koul, and A.L. Moran: Corrosion, 2005, vol. 61, pp. 976-86.

37. B. Sakar, M. Marek, and E.A. Starke: Metall. Trans. A, 1981, vol. 12A, pp. 1939-43.

38. M. Landkof and L. Gal-Or: Corrosion, 1980, vol. 36, pp. 241-46.

39. R.S. Pathania and D. Tromans: Metall. Trans. A, 1981, vol. 12A, pp. 607-12.

40. T. Oka, K. Take, Y. Minamino, K. Hirao, and T. Yamane: $J$. Jpn. Inst. Light Met., 1986, vol. 36, pp. 15-21.

41. H. Kim and S. Pyun: Taehan Kumsok Hakhoe Chi, 1984, vol. 22, pp. 621-31

42. H. Gruhl: Z. Metallkunde, 1962, vol. 53, pp. 670-75.

43. S. Pyun: Metall, 1984, vol. 38, pp. 229-31.

44. H.B. Romans and H.L. Craig: Stress Corrosion Testing, ASTMSTP 425, Philadelphia, PA, 1966, pp. 363-78.

45. W.J. Helfrich: Stress Corrosion Testing, ASTM-STP 425, Philadelphia, PA, 1966, pp. 21-30.

46. Y. Choi, H.C. Kim, and S. Pyun: J. Mater. Sci., 1984, vol. 19, pp. $1517-21$.

47. M.O. Speidel and M.V. Hyatt: Advanced Corrosion Science Technology, vol. 2, Plenum Press, New York, NY, 1972, pp. 115335.

48. J. Onoro and C. Ranninger: J. Mater. Sci., 1999, vol. 35, pp. 509-14.

49. K. Komai, K. Minoshima, and H. Yukimachi: J. Soc. Mater. Sci. Jpn., 1983, vol. 32, pp. 1238-42.

50. S. Ohsaki, Y. Kojima, and T. Takahashi: J. Jpn. Inst. Light Met., 1983, vol. 33, pp. 579-87.

51. S. Osaki: Yomaguchi Daigaku Kogakubu Kenkyu Hokou, 1977, vol. 27 (2), 269-76.

52. M.O. Speidel: Metall. Trans. A, 1975, vol. 6A, pp. 631-51.

53. T. Ohnishi, H. Kojuma, N. Seko, and K. Higashi: J. Jpn. Inst. Light Met., 1986, vol. 36, pp. 272-78.

54. J. Onoro, A. Moreno, and C. Ranninger: J. Mater. Sci., 1989, vol. 24 , pp. $3888-91$

55. F.S. Bovard: Master's Thesis, University of Pittsburgh, 2005.

56. G.M. Scamans, M.F. Frolish, W.M. Rainforth, Z. Zhou, Y. Liu, X. Zhou, and G.E. Thompson: Surf. Interface Anal., 2010, vol. 42 , pp. $175-79$.

57. T.H. Nguyen and R.T. Foley: J. Electrochem. Soc., 1980, vol. 127 , pp. $2563-66$

58. A. Berzin, R.T. Lowson, and K.J. Mirams: Aust. J. Chem., 1977, vol. 30, pp. 1891-1903.

59. D.M. Drazic, S.K. Zecevic, R.T. Atanasoski, and A.P. Despic: Electochima Acta., 1983, vol. 28, pp. 751-55.

60. P.M. Natishan, W.E. Grady, E. McCafferty, D.E. Ramaker, K. Pandya, and A. Russell: J. Eletrochem. Soc., 1999, vol. 146, pp. $1737-40$.

61. A. Kolics, A.S. Besing, P. Baradlai, R. Haasch, and A. Wieckowski: J. Electrochem. Soc., 2001, vol. 148, pp. B251-B259.

62. L. Tomcsanyi, K. Varga, I. Bartik, G. Horanyi, and E. Malczki: J. Electrchim. Acta, 1989, vol. 34, pp. 885-89.

63. N.J.H. Holroyd and M.R. Jarrett: "Corrosion Chemistry within Pits, Crevices and Crack 2," Unpublished Research, Presented at Conference held at Mansfield College, Oxford, UK, 2009.

64. N.J.H. Holroyd, G.M. Scamans, and R. Hermann: in Corrosion Chemistry within Pits, Crevices and Cracks, A. Turnbull, ed., HMSO, London, England, 1987, pp. 495-510.

65. N.J.H. Holroyd, G.M. Scamans, and R. Hermann: in Embrittlement by the Localized Environment, R.P. Gangloff, ed., AIME, Warrendale, PA, 1984, pp. 327-47.

66. M.S. Domak: in Environmentally Assisted Cracking: Science and Engineering, ASTM-STP 1049, W.B Lisagor, T.W. Crocker and B.N. Leis, eds., ASTM, Philadelphia, PA, 1990, pp. 391-409.

67. K.R. Cooper and R.G. Kelly: in Chemistry and Electrochemistry of Stress Corrosion cracking: A Symposium Honoring the Contributions of R.W. Staehle, R.H. Jones, ed., TMS, Warrendale, PA, 2001, pp. 523-42.

68. A. Turnbull: Corrosion, 2001, vol. 57, pp. 175-89. 
69. S. Mostovoy, P.B. Crosley, and E.J. Ripling: J. Mater., 1967, vol. 2, pp. 661-81.

70. H.R. Smith and D.E. Piper: Report D6-24872, The Boeing Company, Seattle, June 1979.

71. K.P. Wong and R.C. Alkire: J. Electrochem. Soc., 1990, vol. 137, pp. 3010-15.

72. Z.A. Foroulis and M.J. Thubrilar: J. Electrochem. Soc., 1975, vol. 122, pp. 1296-301

73. R.T. Foley and T.H. Nguyen: J. Electrochem. Soc., 1982, vol. 129 , pp. 464-67.

74. R.T. Foley: Corrosion, 1986, vol. 42, pp. 277-88.

75. N.J.H. Holroyd: in Environmental Effects on Engineered Materials, R.S Jones, ed., Marcel Decker, Inc., New York, 2000, pp. 173-251.

76. F.E. Watkinson and J.C. Scully: Corros. Sci., 1972, vol. 12, pp. $905-24$.

77. A.H. Le and R.T. Foley: Corrosion, 1984, vol. 40, pp. 195-97.

78. R.C. Doward and K.R. Hasse: Corros. Sci., 1979, vol. 19, pp. $131-40$.

79. Y. Jiang: Final Office of Naval Research Report, Contract N00014-08-0646, April 2011.

80. J. Zhang, S. Kalnaus, M. Behrooz, and Y. Jiang: Metall. Mater. Trans. A, 2011, vol. 42A, pp. 448-60.

81. B.J. Connelly, K.L. Deffenbaugh, M.G. Koul, and A.L. Moran: JOM, 2003, vol. 55, pp. 49-52.

82. A.K. Vasudevan and K. Sadananda: Metall. Mater. Trans. A, 2011, vol. 42A, pp. 396-404.

83. L.M Young: Ph.D. Thesis: University of Virginia, Charlottesville, VA, 1999.

84. K.R. Cooper, L.M. Young, R.P. Gangloff, and R.G. Kelly: Mater. Sci. Forum, 2000, vols. 331-337, pp. 1625-34.

85. L.M. Young and R.P. Gangloff: in Advances in the Metallurgy of Aluminum Alloys, M. Tiryakioglu, ed., ASM International, Materials Park, OH, 2001, pp. 135-40.

86. K.R. Cooper and R.G. Kelly: in Advances in the Metallurgy of Aluminum Alloys, M. Tiryakioglu, ed., ASM International, Materials Park, OH, 2001, pp. 73-82.

87. K.R. Cooper and R.G. Kelly: Corros. Sci., 2007, vol. 49, pp. 2636-62.

88. K.R. Cooper and R.G. Kelly: J. Chromatogr. A., 1999, vol. 850, pp. 381-89.

89. T.H. Nguyen, B.F. Brown, and R.T. Foley: Corrosion, 1982, vol. 38 , pp. 319-26.

90. G.A. Young and J.R. Scully: Metall. Mater. Trans. A, 2002, vol. 33A, pp. 101-15.

91. K. Kitamura and E. Sato: J. Jpn. Inst. Light Met., 1979, vol. 29, pp. $563-67$.

92. A.S. Tetelman and A.J. McEvily: Fracture of Structural Materials, Wiley, New York, 1967, pp. 438-40.
93. G.M. Scamans: Metall. Trans. A, 1980, vol. 11A, pp. 846-50.

94. P. Martin, J.I. Dickson, and J.P. Bailon: Mater. Sci. Eng., 1985, vol. 69, pp. L9-L13.

95. N.J.H. Holroyd and G.M. Scamans: Metall. Mater. Trans. A, 2011, vol. 42A, pp. 3979-98.

96. C.J. Newton and N.J.H. Holroyd: in New Methods for Corrosion Testing Aluminum Alloys, ASTM-STP 1134, V.S. Agarwala and G.M. Ugiansky, eds., ASTM, Philadelphia, PA, 1992, pp. 15379.

97. C.A. Loto and R.A. Cottis: Corrosion, 1989, vol. 45, pp. 13641.

98. M.S. Domack: in Corrosion Cracking, V.S Groel, ed., ASM, Materials Park, OH, 1986, pp. 191-96.

99. J.P. Nordin, D.J. Sullivan, B.L. Phillips, and W.H. Case: Inorg. Chem., 1998, vol. 37, pp. 4760-63.

100. D.J. Sullivan, J.P. Nordin, B.L. Phillips, and W.H. Casey: Geochim. Cosmochim. Acta, 1999, vol. 63, pp. 1471-80.

101. M. Watanabe: J. Phys. Chem. Solids, 2010, vol. 71, pp. 1251-58.

102. T. Magnin, A. Chambreuil, and B. Bayle: Acta Mater., 1996, vol. 44, pp. 1457-70.

103. M. Abe, K. Ouchi, K. Asano, and A. Fujiwara: J. Jpn. Inst. Met., 1981, vol. 45, pp. 1161-69.

104. T.H. Sanders and E.A. Starke: Metall. Trans. A, 1976, vol. 7A, pp. $1407-18$.

105. E.A. Starke: Mater. Sci. Eng., 1977, vol. 29, pp. 99-115.

106. F.S. Lin and E.A. Starke: Mater. Sci. Eng., 1979, vol. 39, pp. 2741.

107. S.W. Ciaraldi, J.L. Nelson, R.A. Yeske and E.N. Pugh: Hydrogen Effects in Metals, I.M. Bernstein and A.W. Thompson, eds., AIME, Warrendale, PA, 1981, pp. 437-47.

108. R. Hermann: Corrosion, 1988, vol. 44, pp. 685-90.

109. F.P. Ford: Corrosion, 1979, vol. 35, pp. 281-89.

110. N. Lampeas and P.G. Koutoukos: Corros. Sci., 1994, vol. 36, pp. 1011-025.

111. M. Metikos-Hukovic, R. Babic, Z. Grubac, and S. Brinic: $J$. Appl. Chem., 1994, vol. 24, pp. 325-31.

112. B. Bavarian, L. Reiner, H. Youssefpour, and I. Juraga: in Corrosion 2005-Paper \#65329, NACE, Houston, 2005.

113. O.D. Sherby, J.L. Lytonn, and J.E. Dorn: Acta Metall., 1957, vol. 5, pp. 219-27.

114. T. Ishikawa and R.B. McLellan: Acta Metall., 1986, vol. 34, pp. 1091-95.

115. G.A. Young and J.R. Scully: Acta Mater., 1998, vol. 18, pp. $6337-49$.

116. J.R. Scully, G.A. Young, and S.W. Smith: Mater. Sci. Forum, 2000, vols. 331-337, pp. 1583-600.

117. S. Ohsaki, Y. Kojima, and T. Takahashi: J. Jpn. Inst. Light Met., 1983, vol. 33, pp. 539-46. 